\title{
STRUCTURAL CHARACTERISATION OF TEXTILE CERAMIC TECHNOLOGY USED AS A CURTAIN WALL
}

\author{
Ernest Bernat ${ }^{a^{*}}$, Lluis Gil ${ }^{a}$, Pere Roca ${ }^{b}$, Vicenç Sarrablo ${ }^{c}$ and Christian Escrig ${ }^{a}$ \\ ${ }^{a}$ Department of Strength of Materials and Engineering Structures \\ Technical University of Catalonia UPC. BarcelonaTech. \\ ETSEIAT, Colom 11. 08222 Terrassa, Spain \\ ${ }^{\mathrm{b}}$ Department of Construction Engineering \\ Technical University of Catalonia UPC. BarcelonaTech. \\ ETSECCPB. Jordi Girona 1-3. 08034 Barcelona, Spain \\ ${ }^{\mathrm{C}}$ Department of Architecture \\ International University of Catalonia. \\ ESARQ, Immaculada 22. 08017 Barcelona, Spain
}

\begin{abstract}
Textile Ceramic Technology (TCT) is a system composed of ceramic units installed in a grid of steel wires. TCT application as a curtain wall which allows ventilation is expected to be an inexpensive, aesthetic and sustainable solution. In order to use TCT as a curtain wall, experimental research about the mechanical response of hanged TCT panels is required. The main aim of this paper is to present the results of this experimental work. Different loading conditions corresponding to gravity and wind forces have been applied on typical TCT panels and the results point out that TCT is sufficiently mechanically competent to be used as a curtain wall. The application range and limitations are summarised.
\end{abstract}

\section{Keywords}

Technological curtain wall, textile ceramic technology, ventilated façade, experimental test

* Corresponding author:

Tel.: +34 937398728; fax: 937398994

E-mail address: ernest.bernat@upc.edu 


\section{Introduction}

Ventilated façades, used because of their energy performance and durability, are typically composed of three layers, namely the internal building façade, an isolation material layer stuck to the internal façade and the external façade which is commonly placed leaving a gap with the insulation layer so that an air cavity is created. This multi-layered structure contributes significantly to the energetic efficiency of the building and to its thermal insulation. This advantage has been proved by López, F. et al. [1] or Seferis, P. et al. [2], among others, and has been specifically noted for ceramic cladding by Stazi, F. et al. [3]. However, the use of ceramic claddings requires normally a manual procedure for placing the external façade and this is one of the main drawbacks that contribute to increase the cost of the system. Nowadays, most of the external façades are curtain walls composed of plates connected to a lightweight structure attached to the building main structure and leaving an air gap allowing the ventilation. Thus, an industrialised solution to improve the production and placement of this curtain walls is necessary. In this way, some rigid panels of bigger dimensions have been used [4]. The application of textile reinforced concrete in the panels production is also noticeable [5]. Moreover, innovative connection systems have been designed as in [6] or [7]. However, a more flexible option is herein presented, namely Textile Ceramic Technology $\left(\mathrm{TCT}^{1}\right)$ applied as a façade.

TCT is a technical material composed of high strength steel wires and ceramic pieces specifically designed for this application. TCT consists of a mesh of steel wires that are woven to form a fabric with irregular wire density, and ceramic bricks or thin light-weight plates inserted within the voids of this steel grid. This system was developed and patented by a research group at Escola Tècnica Superior d'Arquitectura of Universitat Internacional de Catalunya (ESARQ-UIC) [8]. Figure 1 shows a general view of TCT applied to a curtain wall. TCT elements can be folded or rolled, transported easily and suspended from the top of a building to form a ventilated façade system. For curtain wall application, stainless steel wires and lightweight ceramic pieces are used.

TCT was developed to build thin structural masonry shells like those by Eladio Dieste in South America. The mechanical behaviour of TCT when a rigid joint is casted between the pieces is similar to reinforced brick masonry as analysed in [9] or [10]. Its satisfactory results led to conceive other innovative applications of this masonry production system. So far, TCT has been successfully used to build vaulted roofs and pavements. One of the main potential applications of TCT is found in the construction of curtain walls for buildings. However, the use of the system for this application requires a previous specific research, presented in this paper, regarding the supporting and fixing conditions to the structure. It must be noted that, in its application as curtain walls, TCT is used with no mortar or any other sealing at the joints, so that its strength and stability depend exclusively of the mechanical characteristics of the steel mesh and its connection to the building structural system. For all these reasons, a detailed experimental campaign was necessary to characterise the behaviour of this system and to design the needed construction details. The main aim of the present paper is to present and discuss the experimental data in order to validate the use of TCT as a curtain wall. 
It must be also noted that the system herein presented differs from all other commercially existing construction system for external façades due to its genuine combination of steel meshes and bricks. Thus, the result, which includes an air gap between the flexible curtain wall and the building structural façade, does not really fit to the definition of a ventilated façade.

The study followed an experimental approach involving static tests on each different component and dynamic tests on the weaker parts only. Among the specific aims of the research was the determination of the load-bearing capacity of each component and connection, characterizing the global behaviour of the system and proposing some design criteria useful for real applications.

The construction of a TCT curtain wall requires a set of complementary elements. The developed system includes three main parts: the mesh connection element which is fixed at the upper horizontal edge of the TCT sheet; the hanging element which holds the mesh connection element and, thus, supports all the weight of the TCT at the upper end; and the retention element whose aim consists of restraining the out-of-plane movements of the curtain and keeps the TCT sheet at a fixed distance from the building structure. A sketch of these auxiliary elements is shown in Figure 2. As part of the present research, each one of these elements was tested up to failure under quasi-static loading, and the weaker one was also tested under dynamic loads. The description of each test and the specimens used are presented in the subsequent sections.

Assuring a favourable behaviour of TCT when used as curtain wall may foster the use of this faster and cheaper covering system for energetic sustainable façades. The final purpose of the study is to provide useful test setups for this kind of structure components and, even more important, to give some design and construction guidelines in accordance with the loads that the curtain wall is expected to resist. These include the self-weight of the TCT mesh with its ceramic pieces, which is approximately $0.1 \mathrm{kN} / \mathrm{m}^{2}$, and wind pressure. The seismic loading conditions are not considered in this paper because the system is oriented to be applied in non-seismic or moderately seismic areas as the ones where unreinforced brick masonry walls are commonly used as building enclosure (e.g. Spain where the system has been developed). Its application in seismic areas will require further investigation because of the large oscillations that this type of curtain wall might experience.

\section{Materials and methods}

The components used to fix the TCT curtain wall to the building main structure are defined in this section. The test procedure used for testing each element is also described.

\subsection{Testing the mesh connection element}

The mesh connection element consist of an " $\mathrm{L}$ " steel profile and several little steel plates which are screwed to the " $\mathrm{L}$ " profile by pressing the steel wires of the TCT mesh. The joint between the wires (and so the TCT mesh) and the mesh connection element fully relies on the friction between the parts.

Pull out tests were done to determine the load bearing capacity of this type of connection. Two different configurations of the mesh connection element were tested depending on the 
number of wires held by one plate. A common TCT sheet, of a width of approximately $1 \mathrm{~m}$, includes two lateral joints and three interior ones. Each steel plate in the connections is used to fix three wires, in the case of the interior joints, and only one in the case of the lateral joints.

For the pull out test a symmetric sample configuration was used. Two equivalent mesh connection elements were simultaneously tested at the same time. No ceramic elements were placed inside the mesh during these tests. The samples can be observed in Figure 3 and their main characteristics are summarised in Table 1. All plates had dimensions of $68 \mathrm{~mm} \times 30 \mathrm{~mm} \times$ $4 \mathrm{~mm}$ and the " $\mathrm{L}$ " profiles had a section of $40 \mathrm{~mm} \times 40 \mathrm{~mm} \times 4 \mathrm{~mm}$ and were $250 \mathrm{~mm}$ long. All screws (M10 10.9) were tightened at $72 \mathrm{~N} \cdot \mathrm{m}$.

The test procedure (static) involved the following steps:

a) Measuring the geometry with a ruler $(0.5 \mathrm{~mm}$ precision) and a digital calliper $(0.01 \mathrm{~mm}$ precision) and inspecting for any damage or imperfection.

b) Placing the sample in the test setup. Both e ends were fixed to the loading system with clamps to assure the vertical alignment during the test and to prevent the " $\mathrm{L}$ " profile from rotating. Some little plates were used to level each edge. The upper edge was joined with the mobile part of an electromechanical press. The test setup is shown in Figure 4. A Suzpecar electromechanic press with a range of $50 \mathrm{kN}$ and accuracy of $0.001 \mathrm{kN}$ was used.

c) Placing an extensometer by clamping the (or one of the) wire(s) between the profiles to monitor the strain. The strain rate was used as a test control variable during the load application step. This extensometer, manufactured by Sistemas de Ensayo Company, had a range of $50 \mathrm{~mm}$ and an accuracy of $0.01 \mathrm{~mm}$.

d) Applying the loading-unloading cycles under displacement control. The variable controlled was the strain of the instrumented wire. During the tests, the force, the displacement of the upper " $\mathrm{L}$ " profile and the elongation of the monitored wire were simultaneously acquired at $5 \mathrm{~Hz}$ with an HBM MGCPlus DAQ.

Before carrying out these tests, seven complementary tests were done to ascertain that the ceramic pieces would not fall from the steel wires mesh due to the elongation of the wires. The test setup was similar to the previously detailed one but with wider $(60 \mathrm{~cm}$, corresponding to three ceramic pieces in column) and longer $(50 \mathrm{~cm}$, corresponding to three ceramic rows) specimens. The possibility of removing and replacing a ceramic unit with the steel wires mesh in tension was also assessed.

\subsection{Dynamic test of the mesh connection element}

Based on the results of the quasi-static tests on every component, it was concluded that the weaker element of the TCT curtain wall was the mesh connection one. Therefore, some dynamic tests were carried out to determine the strength of this element against cyclic loads like the ones originated by wind. Earthquake effects have not been considered for the moment because the system is aimed to be initially commercialised and utilized only in non-seismic areas (with accelerations under 0.04 times the gravity). Thus, the application of TCT as a curtain wall in seismic areas is regarded as a future development. 
The tested samples were similar to the ones with 1 wire presented in section 2.1 except for having smaller vertical span (see Table 2). The test setup and procedure were specifically developed for this study. Dynamic out-of-plane tests were carried out to determine the maximum out-of-plane oscillation that the samples could resist. Three different angles of oscillation were tested. In the experiment, the samples were subjected to $10000 \mathrm{cycles}$ at frequency of $3 \mathrm{~Hz}$.

The test setup was based on a lever system. At one end a hydraulic actuator (fabricated by MTS with $50 \mathrm{kN}$ range and $0.01 \mathrm{kN}$ accuracy) applied a vertical oscillatory displacement at a frequency of $3 \mathrm{~Hz}$. A rod was used as a fulcrum and the longer arm was connected to the mobile end of the sample. This allowed amplifying the vertical movement to the desired values while maintaining the oscillation frequency. The other end of the sample was fixed to a stiff steel pillar. An intermediate guide was places to support the potentiometer (Waycon Linearpot $100 \mathrm{~mm}$ range and $0.01 \mathrm{~mm}$ precision) which measured the real applied displacements. A picture of the test setup is presented in Figure 5 and the test setup is sketched in Figure 6.

The test procedure (dynamic) involved the following steps:

a) Identifying the sample, measuring its geometry with a metallic ruler (with accuracy of $0.5 \mathrm{~mm}$ ) and a digital calliper (with accuracy of $0.01 \mathrm{~mm}$ ) and inspecting for any damage or imperfection.

b) Placing the sample in the test setup. The sample should be placed in horizontal position and perfectly aligned with the testing machine. A level was used. Neither tension nor compression stresses should appear during the positioning step when the " $\mathrm{L}$ " profiles were fixed to the static support or the mobile part of the testing machine. Thus, the position of the sample could be adjusted by increasing or reducing the length of the longer lever arm.

c) Measuring the geometry of the test setup once it was ready (using a meter with an accuracy of $1 \mathrm{~mm}$ ) and setting the potentiometers in their position and levelled to measure the vertical displacement.

d) Carrying out the tests by applying a vertical oscillatory displacement (using a dynamic hydraulic actuator of a range of $50 \mathrm{kN}$ range an accuracy of $0.01 \mathrm{kN}$ ) at the mobile end of the sample that experienced the desired angular movement. The displacement data at the mobile end of the sample and the force required to produce such displacement were simultaneously acquired at $50 \mathrm{~Hz}$ with an $\mathrm{HBM}$ MGCPlus DAQ. The failure was detected by noticing a change in the mechanical response (see Figures 14, 15 and 17).

The sample which did not break during the fatigue (cyclic) test was tested in direct tension with a test setup similar to that described in in section 2.1 (Figure 4). In this case, the test procedure was limited to the following steps:

a) Placing the sample in the test setup, levelling it and fixing both ends to the mobile and the fixed part of the electromechanical press. A Suzpecar press machine with a range of $50 \mathrm{kN}$ and accuracy of $1 \mathrm{~N}$ was used.

b) Applying a tensile displacement at a constant rate of $10 \mathrm{~mm} / \mathrm{min}$ up to failure. The force and press displacement data were simultaneously acquired at $50 \mathrm{~Hz}$ a $\mathrm{HBM}$ 
MCGPlus DAQ. The displacement was acquired with a potentiometer with range of $1000 \mathrm{~mm}$ and accuracy of $0.01 \mathrm{~mm}$.

\subsection{Testing the retention element}

The retention element is designed to restrain the out-of-plane displacement of the TCT panels when installed as curtain walls. This part consists of two stainless steel elements. The first one

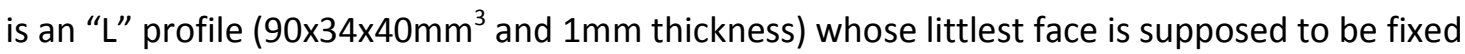
to the building structure. The second one is a specifically designed clamp $\left(100 \times 40 \mathrm{~mm}^{2}\right)$ which embraces two horizontal wires of the TCT. This clamp is fixed to the " $\mathrm{L}$ " profile with a screwed adaptable joint (see Figure 7). This connection allows setting the desired gap between the building structure and the TCT curtain wall leaving a ventilated area. According with the design (see Figure 7) the possible gap between the TCT and the building's structure would range from $60 \mathrm{~mm}$ to $120 \mathrm{~mm}$ and only depended on this retention element. This air gap is larger than the usually considered for ventilated façades (around $40 \mathrm{~mm}$ ). Thus, further studies about the air circulation and the possible thermal benefits of this TCT curtain wall need to be carried out.

Based on the function of these elements, the tests performed aimed to characterize their structural response in a pull-out configuration. The test setup consisted of pulling from the retention element which was fixed with a TCT wire passing through the clamp part. This wire represented the TCT connection point and was kept in a fixed position with the pressure of two " $\mathrm{C}$ " profiles. The retention element was joined to this wire and completely fixed to the mobile part of an electromechanic press (Suzpecar $50 \mathrm{kN}$ range $1 \mathrm{~N}$ precision). The loading process was displacement controlled (1000 $\mathrm{mm}$ range potentiometer with $0.01 \mathrm{~mm}$ precision). The two parts of the retention element were joined (screwed) to allow the sliding. This joint configuration was possible because of the slotted holes of the clamp piece.

The geometry of the samples and the test setup are shown in Figure 7. Three samples (R1, R2 and R3) were tested. No similar tests were found in literature. Thus, a specifically designed method was developed. This procedure consisted of:

a) Identifying the sample, measuring its geometry (digital calliper $0.01 \mathrm{~mm}$ precision) and inspecting for any damage or imperfection.

b) Placing the sample in the test setup. Attaching the retention element to the mobile part of the electromechanical press using a M8 screw and a washer. Inserting a steel wire (like the ones of the TCT fabric) through the head of the clamping part of the retention element. Checking the vertical alignment of the test setup with a level.

c) Applying the loading-unloading cycles with displacement control. Force and displacement of the electromechanic press were simultaneously acquired at $5 \mathrm{~Hz}$ by its own controlling system (fabricated and configured by Sistemas de Ensayos Company). Details of the loading cycles are summarised in Table 3.

\subsection{Testing the hanging element}

The hanging element consists of three steel parts: a C-shaped connection profile $(135 \mathrm{~mm} \mathrm{x}$ $50 \mathrm{~mm}$ and $8 \mathrm{~mm}$ thickness) used to be attached to the building structure, a M16 8.8 bar for the system levelling and a steel plate $\left(120 \times 40 \times 15 \mathrm{~mm}^{3}\right)$ where the mesh connection element will be 
fixed. All internal lock nuts were pre tighten to $210 \mathrm{Nm}$ torque when mounting the hanging element.

Two different test types were performed. For the first one, a punctual load was applied perpendicular to the cantilever plate (test $1, \mathrm{~T} 1$ ) in order to represent the weight action of the TCT system. In contrast, this plate was pulled-out in the second test type (test 2, T2) which was specifically intended to study the behaviour against horizontal loads like those caused by the wind. The procedure of both tests is detailed later on.

In addition, two different sample configurations were defined depending on the position of the M16 levelling bar. With this bar placed the nearest to the C-shaped connection profile (situation 1, S1, the edge of the plate was placed at $25 \mathrm{~mm}$ from the web of the C-shaped profile) and with this bar placed the furthest from the C-shaped connection profile (situation 2, $\mathrm{S} 2$, the edge of the plate was placed at $50 \mathrm{~mm}$ from the web of the C-shaped profile). Tests T1 were performed with both sample configurations S1 and S2 whereas tests T2 were carried out on samples with $\mathrm{S} 2$ adjustment only. Tests sketches are shown in Figure 8.

\subsubsection{Test $\mathrm{T} 1$ procedure and calculations}

In this testing configuration, the hanging element was attached to a rigid structural frame with the use of two screwed bars which passed across two corresponding holes in the web of the Cshaped profile (see Figure 8 left and middle). Three samples from both configurations (S1 and S2) were tested according to the following steps:

a) Identifying the sample, measuring its geometry (using a digital calliper $0.01 \mathrm{~mm}$ precision) and inspecting for any damage or imperfection.

b) Placing the sample in the test setup by fixing the hanging element to the rigid frame structure assuring the vertical alignment with a level. Approaching the loading tool up to the contact with the sample (manual control of the actuator).

c) Applying the load with a hydraulic actuator (fabricated and configured by MTS, with $250 \mathrm{kN}$ range and $0.1 \mathrm{kN}$ precision) following the loading-unloading cycles summarised with Table 4. The force and displacement of the loading tool were continuously registered at $50 \mathrm{~Hz}$ by the MTS control and acquisition system. The displacement was measured with the $250 \mathrm{~mm}$ range and $0.01 \mathrm{~mm}$ precision LVDT of the actuator. The test was stopped at reaching $25 \mathrm{~mm}$ displacement.

This testing procedure was indistinctly used for both samples configurations (S1 and S2).

The minimum horizontal load $(\mathrm{H})$ that would cause the slipping of the M16 bar along the Cshaped profile was calculated with (Eq. 1) using the data obtained from the tests T1 on samples S1. (Eq. 1) was obtained from the equilibrium conditions and considering the real geometry of the system represented in Figure 9: 


$$
\mathrm{H}=3 \mathrm{Fb} / 2 \mathrm{a}=0.9054 \mathrm{~F}
$$

\subsubsection{Test $\mathrm{T} 2$ procedure}

Three samples with $\mathrm{S} 2$ configuration were tested by pulling the plate of the hanging system (T2 test). The C-shaped profile of the samples was fixed to a horizontal steel plate by using two screws so the rectangular hanging plate stayed vertical. A hole in this hanging plate allowed connecting the specimen with the loading system (MTS hydraulic actuator of $250 \mathrm{kN}$ range and $0.1 \mathrm{kN}$ precision) using a pinned connection. The test setup is sketched in Figure 8 (right). The testing procedure consisted of:

a) Identifying, measuring (with a digital calliper $0.01 \mathrm{~mm}$ precision) and inspecting the sample.

b) Connecting the hanging element to the support by using two screwed bars. The sample should be vertically aligned (using a level) with the loading system. A bolt (see Figure 8) was used to connect the specimen with the testing machine previously placed in position near the sample using the manual control.

c) Applying the loading-unloading cycles according with Table 4 and recording the force and displacement values. The displacement was measured, like for the previous test setup, using a $250 \mathrm{~mm}$ range and $0.01 \mathrm{~mm}$ precision internal LVDT of the MTS actuator. The test finished when reaching $15 \mathrm{~mm}$ displacement.

Table 5 summarises the samples tested and the tests carried out with hanging elements.

\section{Experimental results and discussion}

The results of the experimental tests carried out within this research are presented in the following sections. Results on each of the curtain wall elements used for its connection to the structure (mesh connection, hanging and retention elements) are separately presented and discussed.

\subsection{Mesh connection element}

\subsubsection{Static tests}

Regarding the experimental results of the tests on the central joint mesh connection elements (C1, C2 and C3) it was observed that the force-displacement behaviour remained linear up to $3 \mathrm{kN}$ in all cases. Moreover, the minimum strength was over $5.2 \mathrm{kN}$ (corresponding to $\mathrm{C} 3$ sample).

Figure 10 shows an analogue response for the three samples along the first loading-unloading cycle. The response differed only in the last stages when the system had already shown permanent strains.

The response of the specimen was characterized by the following aspects:

- Up to approximately $3 \mathrm{kN}$ the two external wires of the sample (Figure 11 partially lost their waved shape but the wires kept perfectly connected to the " $\mathrm{L}$ " profile. A linear response was obtained up to the mentioned load. 
- From $3 \mathrm{kN}$ and up to failure, the three wires slid from the "L" profile but the central one preserved its wavy shape, showing that it was not supporting so much force as the external ones.

- It was also observed that the two external wires did not work in a symmetric way. One of them showed larger deformation than the other because of the geometric imperfections.

The Figure 11 shows the sliding failure observed in all tests. By comparing the initial and final conditions of the sample, it is possible to notice the stretching and sliding process experienced by the external wires. The remaining wavy shape of the central wire indicates that it was not as loaded as the external ones.

The experimental results of the static tests on the end joint mesh connection elements - E1, E2 and E3 - show a linear response up to $1 \mathrm{kN}$, although plastic strains were measured for loads over 500N. These plastic strains are associated with the change of the wire's shape (loss of wavy pattern). All samples resisted a load over $2.8 \mathrm{kN}$ in direct tension. Their mechanical response is plotted in Figure 12. This graph shows a bilinear behaviour for all specimens. The initial loading-unloading cycles are similar for all them and the curves are continuous up to the ductile failure.

The end joint samples (E1, E2 and E3) behaved linearly while the wire was losing its wavy shape during the initial loading-unloading cycles. This response is analogue to the one observed for the previous tests with central joints (C1, C2 and C3). The sliding process, which begins at approximately $2 \mathrm{kN}$ (see Figure 12 ) is represented by the decrease of the slope of the experimental curves (Figure 10 and Figure 12). The failure takes place when the wire is disconnected from the "L" profile.

Figure 13 shows the initial and final state of the sample E4. A sliding failure was observed after the stretching of the wire. Table 1 summarises the maximum load applied for each specimen.

The previous tests (aimed to adjust the testing method as mentioned before) brought two qualitative remarkable results. The first one is that the ceramic pieces did not fall when a tensile force was applied on the TCT. The second result is the feasibility of replacing a ceramic piece easily by separating the wires, removing the piece and tightening the wires again. This procedure was carried out by hand in approximately 6 minutes by a non-expert person. After the replacement operation the piece was perfectly aligned and remained in its position during the tensile tests, with no movements. Thus, the maintenance of this system is simple but requires time if the ceramic pieces resulted damaged. However, the ceramic pieces are well known for their durability at environmental conditions.

\subsubsection{Dynamic tests}

The Figure 14 and Figure 15 show the variation of the force-displacement response of the mobile end of the samples E4 and E5 respectively. The graphs represent the data from the beginning of the test to a stage near the failure of the specimen. The force-displacement measurements are also presented for the failed condition to prove that the failure can be detected as a significant change of trend in the diagrams. 
The sample E4 (tested with a displacement oscillation corresponding to an angle of $\pm 15^{\circ}$, Figure 14) resisted approximately 100 oscillation cycles according with the experimental data. The load range associated with the imposed displacement was $400 \mathrm{~N}$. Similarly, the load range for the sample E5 was $650 \mathrm{~N}$. E5 was tested with a displacement oscillation corresponding to an angle of $\pm 5^{\circ}$ (see Figure 15). This specimen (E5) resisted around 1600 cycles. The larger strength against cyclic loads of sample E5, if compared with E4, agrees with the corresponding lower oscillation angle. The failure cause for E4 and E5 cases was the rupture of the wire in the fixation point. Figure 16 shows this failure mode.

The sample E6 (tested with a displacement oscillation corresponding to an angle of $\pm 1^{\circ}$, Figure 17) was tested up to approximately 10000 cycles without any appreciable damage. The load range associated with this imposed movement was $200 \mathrm{~N}$. In addition, it was noticed that the mechanical response of $\mathrm{E} 6$ changed during the test by reducing about $20 \%$ the loading range needed to apply the required movement $\left( \pm 1^{\circ}\right)$. Figure 17 shows this effect by comparing the initial and final plots.

After the dynamic test, sample E6 was subjected to a static direct tension test analogue to the one applied to samples E1 to E3. This additional experiment was aimed to evaluate the effect of the cyclic loading process on the mechanical capacity of this mesh connection element. Figure 18 shows the maximum load bearing capacity of the sample E6 (2230N) which was about $28 \%$ lower than the mean value $(3111 \mathrm{~N})$ of the comparable static tests on samples E1 to E3. Thus, the cyclic load caused a reduction of the mechanical capacity of the mesh connection element. However, the sample behaved linear up to $1 \mathrm{kN}$ like E1 to E3 did.

\subsubsection{Discussion on the mesh connection elements}

The end joint of the mesh connection showed a linear response up to $1 \mathrm{kN}$ for all tested cases, including the one previously loaded with cyclic displacements. (E6). Thus, based on the experimental results, it seems reasonable to set the maximum service load of the mesh connection extreme joint at $1 \mathrm{kN}$ in order to ensure the structural safety of the element. In the same way, the central joint showed a linear response up to $3 \mathrm{kN}$ for all cases, being this one the safety limit considered for design reasons. Taking into account that each TCT panel intended to be used as curtain wall has 3 central joints and 2 end joints, the maximum force that the mesh connection element can bear is $11 \mathrm{kN}$.

Taking into account that a typical studied TCT curtain wall weights $0.1 \mathrm{kN} / \mathrm{m}^{2}$ and that each panel is approximately $1 \mathrm{~m}$ wide, the maximum length of each panel must be limited to $110 \mathrm{~m}$ in order to keep the mesh connection element within its safety range. This result shows the suitability of the TCT system for the real application, since the panels are not supposed to exceed a length of $25 \mathrm{~m}$ in curtain walls.

It has to be observed that the previous calculations consider that all the weight of the TCT panel is hanging from the upper mesh connection element. For real applications, the TCT would hang free except for the retention elements which would restrain its horizontal movements but allow the vertical ones (the vertical wires would pass through the retention elements). Thus, the thermal loads would cause a variation of the length of the curtain wall but would not generate stresses on any of the components of the system. The variation of length would be of around $2.5 \mathrm{~cm}$ for a $25 \mathrm{~m}$ long panel subjected to a temperature variation of $50^{\circ} \mathrm{C}$ ) 
It has to be noticed that this kind of flexible curtain wall cannot reach the ground because of safety reasons related with vandalism. Then, a fixed vertical length might not be necessary. The TCT curtain wall may be installed with no restrictions of the vertical displacement except for the hanging point at the top. In this situation, the thermal loads cause a non-stressed deformation of the TCT.

\subsection{Retention element static tests}

Figure 19 shows the results of the tests on the retention elements. A discontinuity in the structural response (punctual decrease of the load) is observed for loads between $2.7 \mathrm{kN}$ and $3.1 \mathrm{kN}$ depending on the sample. Nevertheless, the maximum capacity reached values over $6 \mathrm{kN}$ for all specimens. The initial linear response is maintained up to $1 \mathrm{kN}$ for all cases.

The failure mode was the same for the three samples. First, the " $\mathrm{L}$ " profile and the washer used in the connection with the test machine bended. Then, the load increased up to the shear failure of the wire which represented the TCT mesh in this test. This local failure was the end of the test. The TCT wires were the limiting part of the retention system. Figure 20 shows the damage of a tested retention element.

\subsubsection{Discussion on the retention elements}

The retention elements behave linearly up to $1 \mathrm{kN}$. Thus, this is the value which should be set as a design limit for the out-of-plane loading conditions. For example, considering a wind pressure of $0.6 \mathrm{kN} / \mathrm{m}^{2}$ (maximum pressure according with Spanish standard), one retention element would be required each $1.5 \mathrm{~m}^{2}$. Different solutions suitable for variable wind pressures can be calculated taking into account the maximum tensile force set per each retention element: $1 \mathrm{kN}$.

\subsection{Hanging element static tests}

Figure 21 shows the results of the tests concerning the cantilever plate of the hanging element (T1 test) when the sample was set according with the configuration S1 (in which the M16 bar could slip along the holes of the " $\mathrm{C}$ " shaped profile). Similarly, Figure 22 presents the results of the tests $\mathrm{T} 1$ on the hanging elements with the $\mathrm{S} 2$ configuration (with prevented slipping failure).

According with the results, the hanging element can bear a maximum load over $8 \mathrm{kN}$ with the steel plate working as a cantilever and the $\mathrm{S} 1$ configuration. This load increased over $11 \mathrm{kN}$ if the slipping failure was prevented (S2 configuration). In fact, the slipping process caused the decrease of the maximum applied load shown in the Figure 21 (S1 configuration). The decrease of the load ranged between $6 \mathrm{kN}$ ( $\mathrm{H} 3$ sample) and $8 \mathrm{kN}$ ( $\mathrm{H} 1$ sample) depending on the specimen.

Based on the experimental results and applying the equation (Eq. 1), the average horizontal threshold load which caused the slipping process is calculated and its value is $6.4 \mathrm{kN}$. This force value is over the linearity limit which is conservatively set at $4 \mathrm{kN}$ by observing Figure 21 and Figure 22. Thus, the slipping phenomena should not occur if the use of the hanging element is limited within its linear range. 
Tests T1 finished when the displacement of the loading system reached $25 \mathrm{~mm}$. However, the load was still increasing (see Figure 21 and Figure 22). Thus, the ultimate capacity of the hanging element might be greater than the maximum measured one. The failure mode of samples $\mathrm{H} 1$ to $\mathrm{H} 3$ ( $\mathrm{S} 1$ configuration, allowing the bar to slid) involved the rotation of the M16 bar and bending of the wings of the " $\mathrm{C}$ " profile (see Figure 23 left). In contrast, the " $\mathrm{C}$ " profile preserved its original geometry and the M16 bar kept its vertical position for the samples with the S2 configuration (sliding impeded). In this second case, the steel plate concentrated the deformation as it was working as a perfect cantilever, see Figure 23 (right).

The Figure 24 shows the results of the tests carried out to study the effect of the horizontal forces on the hanging elements (T2 test setup). The three samples ( $\mathrm{H} 7, \mathrm{H} 8$ and $\mathrm{H} 9$ ) behaved similarly with an initial linear response up to $10 \mathrm{kN}$ followed by a softening due to the bending of the M16 bar. The maximum measured load was over $32 \mathrm{kN}$ for all cases. However, it has to be remarked that the tests were stopped at $15 \mathrm{~mm}$ deformation for safety reasons. This was before reaching the ultimate capacity which might correspond to a higher load. At the end of the test, the M16 bar and the wings of the " $\mathrm{C}$ " profile were plastically bended (see Figure 25).

\subsubsection{Discussion on the hanging elements}

Taking into account the experimental results, the load bearing capacity of the hanging elements in the gravity direction (perpendicular to the steel plate of the element) should be limited to $4 \mathrm{kN}$ to assure a linear response. This is a suitable limit design value for the TCT curtain walls.

Knowing that a common TCT curtain wall weights $0.1 \mathrm{kN} / \mathrm{m}^{2}$ and each panel is approximately $1 \mathrm{~m}$ wide, the maximum length of each panel is set to $40 \mathrm{~m}$ to keep the hanging elements working in their linear range. Nevertheless, it is recommended to avoid exceeding a length of $25 \mathrm{~m}$ for transportation and construction reasons. Thus, a hanging element for each TCT panel might be enough to carry the weight, although two elements symmetrically placed are necessary for stability reasons.

Regarding the out-of-plane loads (e.g. wind) the maximum capacity of a hanging element is $3.6 \mathrm{kN}$. This value has been calculated from the maximum vertical load defined before, $4 \mathrm{kN}$, and (Eq. 1). The limiting criterion has been to avoid the sliding phenomenon of the bar which is part of the hanging element. Nevertheless, this horizontal load is far larger than the out-ofplane load that a retention element can bear $(1 \mathrm{kN})$. Thus, the hanging element is not the limiting part against the out-of-plane loads.

\section{Conclusions}

The application of the TCT system as a curtain wall has been proved to accomplish all the studied structural requirements. All connection and installation elements (mesh connection, hanging and retention devices) and the TCT mesh itself can resist the gravity expected wind loads with a satisfactory safety factor. In fact, the application range of the system has been set by keeping all the structural elements in the linear behaviour range. This hypothesis simplifies the design and provides a comfortable safety margin. 
It is also worth noticing that five new test procedures have been presented in detail. These procedures have been proved to be effective in characterising the structural response of a flexible TCT curtain wall system. The development of these test procedures and setups was made necessary by the particularities of this original type of curtain wall. These procedures have been successfully implemented in laboratory conditions.

Simplified and general design rules have been presented based on the experimental results. The proposed rules are aimed to determine the maximum panel length and the number of retention elements which are necessary. However, the application of the TCT as a curtain wall does not have to be limited to these rules. Actually, the experiments carried out have provided a wider technical basis. This information allows the design of optimized solutions adapted to almost any architectural requirement in non-seismic areas. The research presented is expected to be useful for any practitioner or researcher interested in new applications using hanged TCT elements.

Finally, the research has demonstrated the satisfactory structural performance of the studied system. The TCT system is a functional, flexible, durable and structurally competent solution to produce curtain walls. However, its application in seismic areas would need further investigation, including the possible development of stiffer retention elements.

\section{Acknowledgements}

The authors wish to acknowledge Mr. Francesc Puigvert for providing essential support in the experimental campaign.

\section{Bibliography}

[1] López FP, Jensen RL, Heiselberg P, Ruiz de Adana Santiago M. Experimental analysis and model validation of an opaque ventilated façade. Build Environ 2012; 56:265-75.

[2] Seferis P, Strachan P, Dimoudi A, Androutsopoulos A. Investigation of the performance of a ventilated wall. Energ Buildings 2011;43:2167-78.

[3] Stazi F, Tomassoni F, Vegliò A, Di Perna C. Experimental evaluation of ventilated walls with an external clay cladding. Renew Energ 2011;36:3373-85.

[4] Paricio ECl, Pardal C, Paris O, Rafols I, Bermejo F. Light exterior pane for ventilated façade. US Patent EP2010018799320101019, 2011.

[5] Hegger J, Kulas C, Hortsmann M. Spatial textile reinforcement structures for ventilated and sandwich façade elements. Adv Struct Eng 2012;15:665-76.

[6] Sotillo B, Angel M. Structure and achoring system for ventilated façade plates and assembly thereof. US Patent EP20080380119 20080418, 2009.

[7] Luque F. Construction system for ventilated façade wall. US Patent EP2010038221020100729, 2011. 
[8] Sarrablo-Moreno V. Flexible sheet of bricks for construction of architectural elements, and method for manufacture of said sheet. US Patent US 2011/0047914, 2011.

[9] Roca P, Lopezalmansa F, Miquel J, Hanganu A. Limit analysis of reinforced masonry vaults. Eng Struct 2007;29:431-9.

[10] López-Almansa F, Sarrablo V, Lourenço PB, Barros J, Roca P, da Porto F, et al. Reinforced brick masonry light vaults: Semi-prefabrication, construction, testing and numerical modeling. Constr Build Mater 2010;24:1799-814. 


\section{Tables}

Table 1. Geometric characteristics of the tested samples of mesh connection elements and quasi-static tests results.

Table 2. Geometric characteristics of the dynamically tested samples of mesh connection elements and tests results.

Table 3. Loading process of the retention elements

Table 4. Loading procedure for hanging elements

Table 5. Tested hanging elements, configuration and test procedure summary 


\begin{tabular}{cccccc} 
Sample & $\begin{array}{c}\# \\
\text { wires }\end{array}$ & $\begin{array}{c}\text { Vertical span } \\
(\mathbf{m m})\end{array}$ & $\begin{array}{c}\text { Load at } \mathbf{0 . 2 \%} \\
\text { strain }(\mathbf{N})\end{array}$ & $\begin{array}{c}\text { Load at 3mm } \\
\text { deformation }(\boldsymbol{N})\end{array}$ & $\begin{array}{c}\text { Maximum load } \\
\text { (N) }\end{array}$ \\
\hline C1 & 3 & 231 & 642 & 942 & 6449 \\
\hline C2 & 3 & 236 & 1034 & 4852 & 6215 \\
\hline C3 & 3 & 239 & 1560 & 2991 & 5240 \\
\hline E1 & 1 & 239 & 283 & 1224 & 3182 \\
\hline E2 & 1 & 233 & 83 & 300 & 3334 \\
\hline E3 & 1 & 236 & 827 & --- & 2817
\end{tabular}

Table 1. Geometric characteristics of the tested samples of mesh connection elements and quasi-static tests results.

\begin{tabular}{cccccc} 
Sample & $\begin{array}{c}\# \\
\text { wires }\end{array}$ & $\begin{array}{c}\text { Vertical span } \\
(\mathbf{m m})\end{array}$ & $\begin{array}{c}\text { Oscillation angle } \\
(\mathbf{(})\end{array}$ & Failure & $\begin{array}{c}\text { Maximum load } \\
(\mathbf{N})\end{array}$ \\
\hline E4 & 1 & 120.6 & \pm 15 & $\begin{array}{c}\text { Failed at } 100 \\
\text { cycles }\end{array}$ & --- \\
\hline E5 & 1 & 120.7 & \pm 5 & $\begin{array}{c}\text { Failed at } 1600 \\
\text { cycles }\end{array}$ & --- \\
\hline E6 & 1 & 125.0 & \pm 1 & $\begin{array}{c}\text { Resisted 10000 } \\
\text { cycles }\end{array}$ & 2230 \\
\hline
\end{tabular}

Table 2. Geometric characteristics of the dynamically tested samples of mesh connection elements and tests results.

\begin{tabular}{cccc} 
Step & Direction & Velocity $(\mathbf{m m} / \mathbf{m i n})$ & Up to \\
\hline 1 & Loading & 1 & $1 \mathrm{~mm}$ displacement \\
\hline 2 & Unloading & 2 & ON force \\
\hline 3 & Loading & 2 & $2 \mathrm{~mm}$ displacement \\
\hline 4 & Unloading & 5 & ON force \\
\hline 5 & Loading & 5 & $5 \mathrm{~mm}$ displacement \\
\hline 6 & Unloading & 10 & ON force \\
\hline 7 & Loading & 10 & 10mm displacement \\
\hline 8 & Unloading & 20 & ON force \\
\hline 9 & Loading & 20 & Failure \\
\hline & Table 3. Loading process of the retention elements
\end{tabular}




\begin{tabular}{ccccc} 
Step & Direction & Control & Velocity & Up to \\
\hline L1 & Loading & Displacement & $2 \mathrm{~mm} / \mathrm{min}$ & $2 \mathrm{~mm}$ displacement \\
\hline K1 & Constant & Displacement & $0 \mathrm{~mm} / \mathrm{min}$ & $10^{\prime \prime}$ \\
\hline U1 & Unloading & Force & $10 \mathrm{kN} / \mathrm{min}$ & $0 \mathrm{kN}$ \\
\hline K2 & Constant & Displacement & $0 \mathrm{~mm} / \mathrm{min}$ & $10^{\prime \prime}$ \\
\hline L2 & Loading & Displacement & $2 \mathrm{~mm} / \mathrm{min}$ & $4 \mathrm{~mm}$ displacement \\
\hline K3 & Constant & Displacement & $0 \mathrm{~mm} / \mathrm{min}$ & $10^{\prime \prime}$ \\
\hline U2 & Unloading & Force & $10 \mathrm{kN} / \mathrm{min}$ & $0 \mathrm{kN}$ \\
\hline K4 & Constant & Displacement & $0 \mathrm{~mm} / \mathrm{min}$ & $10^{\prime \prime}$ \\
\hline L3 & Loading & Displacement & $2 \mathrm{~mm} / \mathrm{min}$ & $6 \mathrm{~mm}$ displacement \\
\hline K5 & Constant & Displacement & $0 \mathrm{~mm} / \mathrm{min}$ & $10^{\prime \prime}$ \\
\hline U3 & Unloading & Force & $10 \mathrm{kN} / \mathrm{min}$ & $0 \mathrm{kN}$ \\
\hline K6 & Constant & Displacement & $0 \mathrm{~mm} / \mathrm{min}$ & $10^{\prime \prime}$ \\
\hline L4 & Loading & Displacement & $2 \mathrm{~mm} / \mathrm{min}$ & $8 \mathrm{~mm} \mathrm{displacement}$ \\
\hline K7 & Constant & Displacement & $0 \mathrm{~mm} / \mathrm{min}$ & $10^{\prime \prime}$ \\
\hline U4 & Unloading & Force & $20 \mathrm{kN} / \mathrm{min}$ & $0 \mathrm{kN}$ \\
\hline K8 & Constant & Displacement & $0 \mathrm{~mm} / \mathrm{min}$ & $10^{\prime \prime}$ \\
\hline L5 & Loading & Displacement & $2 \mathrm{~mm} / \mathrm{min}$ & $10 \mathrm{~mm} \mathrm{displacement}$ \\
\hline K9 & Constant & Displacement & $0 \mathrm{~mm} / \mathrm{min}$ & $10^{\prime \prime}$ \\
\hline U5 & Unloading & Force & $20 \mathrm{kN} / \mathrm{min}$ & $0 \mathrm{kN}$ \\
\hline K10 & Constant & Displacement & $0 \mathrm{~mm} / \mathrm{min}$ & $10^{\prime \prime}$ \\
\hline L6 & Loading & Displacement & $2 \mathrm{~mm} / \mathrm{min}$ & $\left.15 / 25 \mathrm{~mm} \mathrm{displacement}{ }^{*}\right)$ \\
\hline K11 & Constant & Displacement & $0 \mathrm{~mm} / \mathrm{min}$ & $10^{\prime \prime}$ \\
\hline U6 & Unloading & Force & $20 \mathrm{kN} / \mathrm{min}$ & $0 \mathrm{kN}$ \\
\hline K12 & Constant & Displacement & $0 \mathrm{~mm} / \mathrm{min}$ & $10^{\prime \prime}$ \\
\hline & & &
\end{tabular}

$\left(^{*}\right) 25 \mathrm{~mm}$ for tests T1 and $15 \mathrm{~mm}$ for tests T2

Table 4. Loading procedure for hanging elements

\begin{tabular}{ccc} 
Sample & Configuration & Test \\
\hline $\mathrm{H} 1, \mathrm{H} 2, \mathrm{H} 3$ & $\mathrm{~S} 1$ & $\mathrm{~T} 1$ \\
\hline $\mathrm{H} 4, \mathrm{H} 5, \mathrm{H} 6$ & $\mathrm{~S} 2$ & $\mathrm{~T} 1$ \\
\hline $\mathrm{H} 7, \mathrm{H} 8, \mathrm{H} 9$ & $\mathrm{~S} 2$ & $\mathrm{~T} 2$ \\
\hline
\end{tabular}

Table 5. Tested hanging elements, configuration and test procedure summary 


\section{Figures}

Figure 1. External TCT curtain wall (www.flexbrick.es)

Figure 2. Sketch of the characterised parts of a TCT curtain wall

Figure 3. Initial state of the samples. Mesh connection elements. Central element with three wires (left) and end element with one wire (right). In front (left) and back (right) view of the connection system with the little plates screwed to the " $\mathrm{L}$ " profiles subjecting the wires.

Figure 4. Test setup for the mesh connection elements. Sample $\mathrm{C} 1$ at the beginning of the test Figure 5. Test setup for the dynamic experiment on the mesh connection element

Figure 6. Sketch of the test setup for the dynamic experiments on the mesh connection elements

Figure 7. Retention element (left) and corresponding test setup (right)

Figure 8. Sketch of the tests setups on hanging elements. From left to right, test T1 on sample configuration S2, test T1 on sample configuration S1 and test T2 on sample configuration S2 Figure 9. Sketch of the equilibrium forces

Figure 10. Force-Displacement behaviour of the mesh connection element corresponding to a central joint

Figure 11. Initial (left) and final (right) state of the mesh connection element C2

Figure 12. Force-Displacement behaviour of the mesh connection element corresponding to the end joint

Figure 13. Initial (left) and final (right) state of the mesh connection element E3

Figure 14. Force-displacement response of the free end of the sample E4 at the beginning of the test, near the failure and once the element failed

Figure 15. Force-displacement response of the free end of the sample E5 at the beginning of the test, near the failure and once the element failed

Figure 16. Final state of the sample E5 which failed by fatigue

Figure 17. Force-displacement response of the free end of the sample E6 at the beginning of the test and after 10000 cycles.

Figure 18. Tension-displacement of the sample E6 quasi-statically tested after the dynamic test

Figure 19. Experimental tensile response of the retention elements R1, R2 and R3

Figure 20. Retention element failure mode (left) by breaking the TCT wire and " $\mathrm{L}$ " profile bending (right) produced before failure

Figure 21. Experimental response of the hanging element with configuration S1 when loaded according with test setup T1

Figure 22. Experimental response of the hanging element with configuration S2 when loaded according with test setup T1

Figure 23. Failure mode of samples H2 (T1_S1) and H4 (T1_S2)

Figure 24. Experimental response of the hanging element when loaded according with test setup T2 (sample configuration S2)

Figure 25. Failure of the sample H9, hanging element, under horizontal loads (T2) 


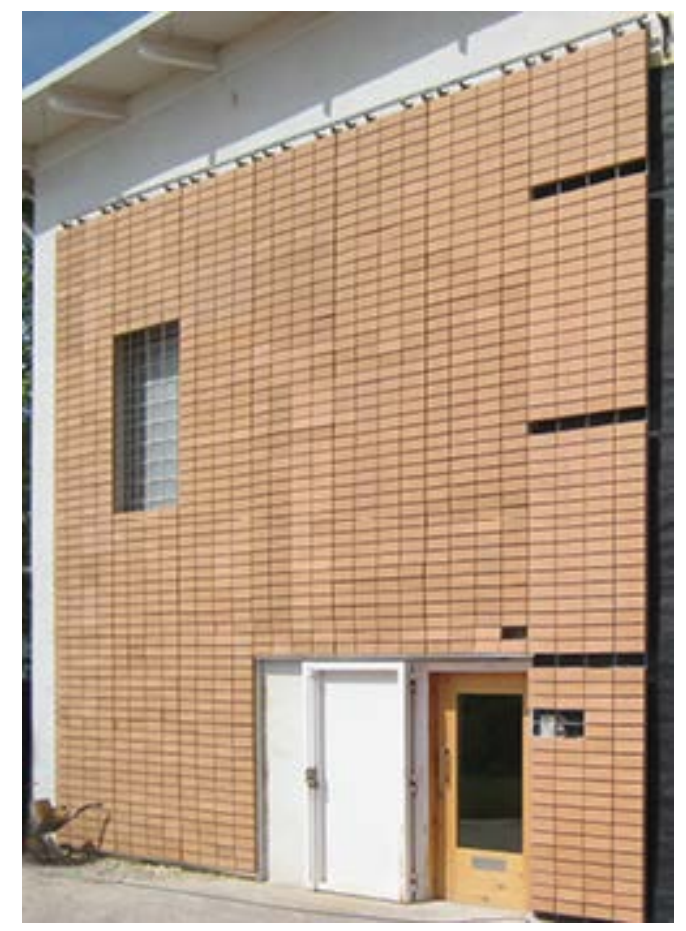

Figure 1. External TCT curtain wall (www.flexbrick.es)

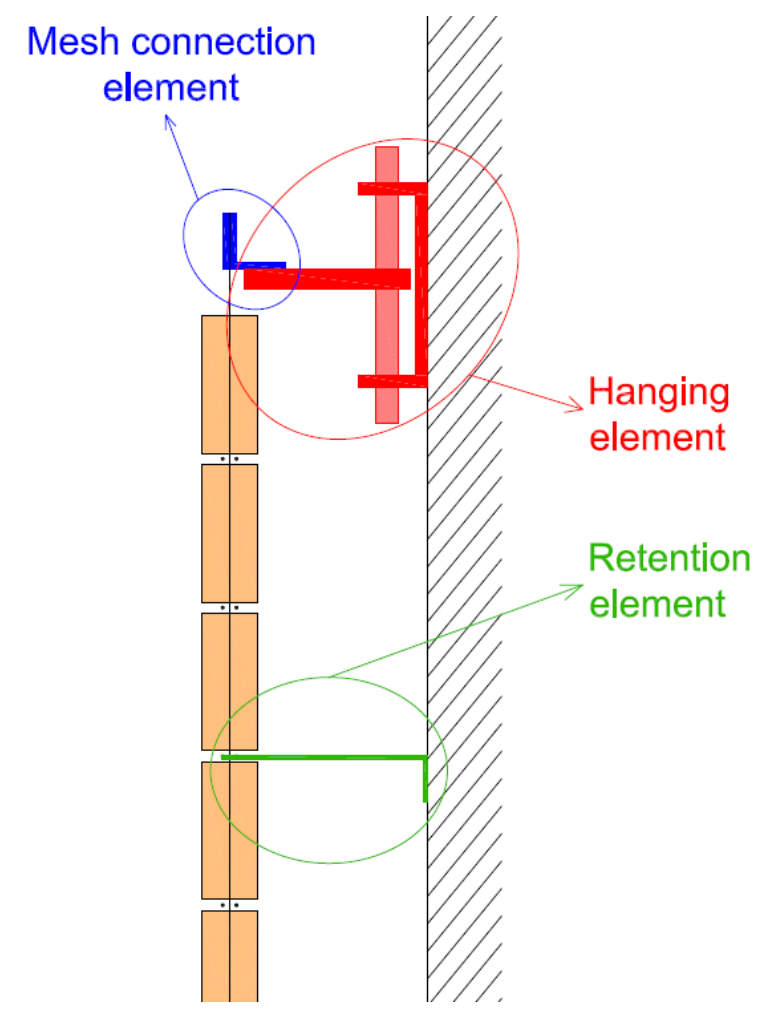

Figure 2. Sketch of the characterised parts of a TCT curtain wall 


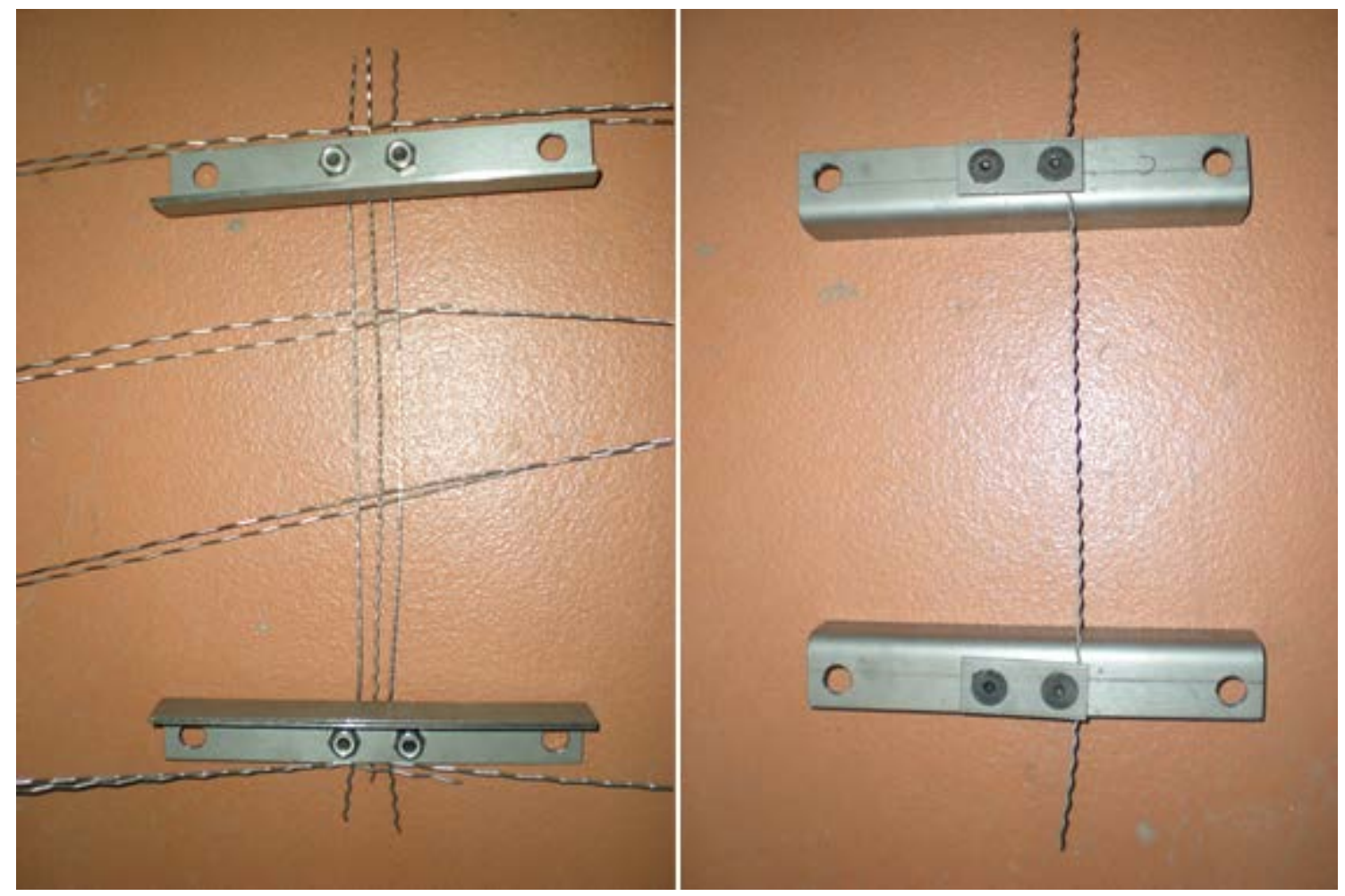

Figure 3. Initial state of the samples. Mesh connection elements. Central element with three wires (left) and end element with one wire (right). In front (left) and back (right) view of the connection system with the little plates screwed to the "L" profiles subjecting the wires.

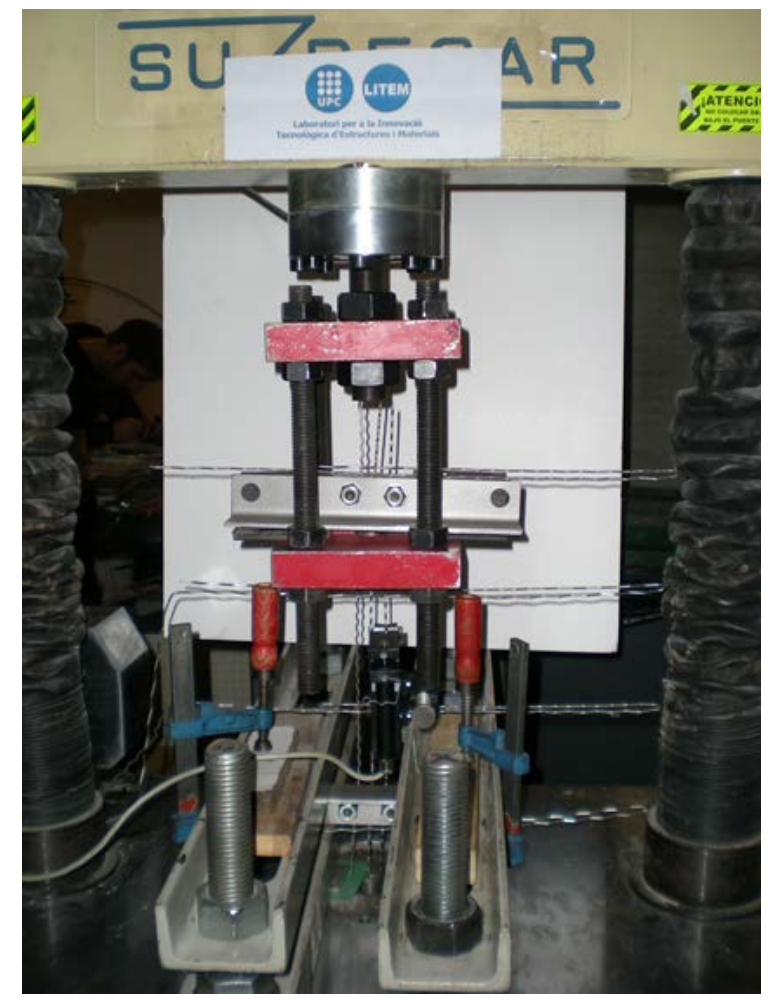

Figure 4. Test setup for the mesh connection elements. Sample $\mathrm{C} 1$ at the beginning of the test 


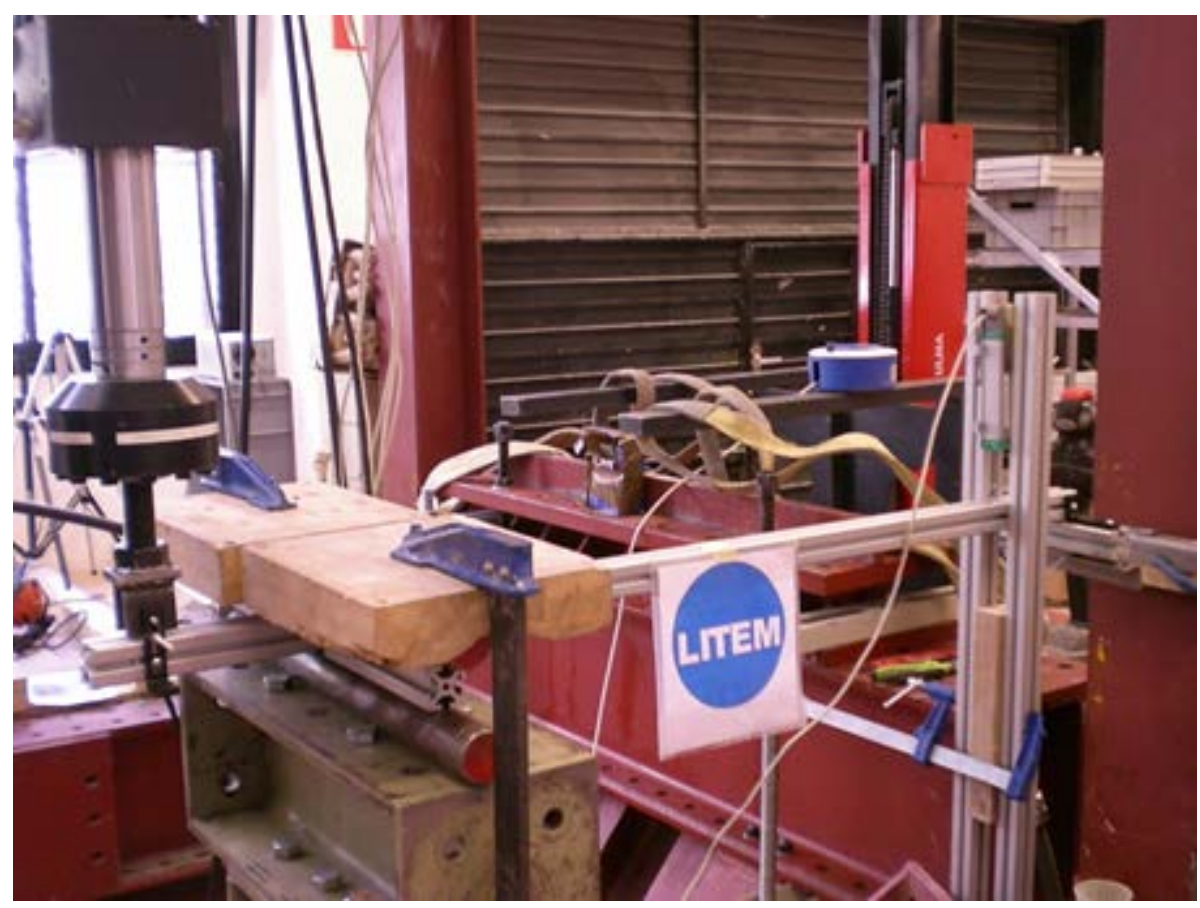

Figure 5. Test setup for the dynamic experiment on the mesh connection element
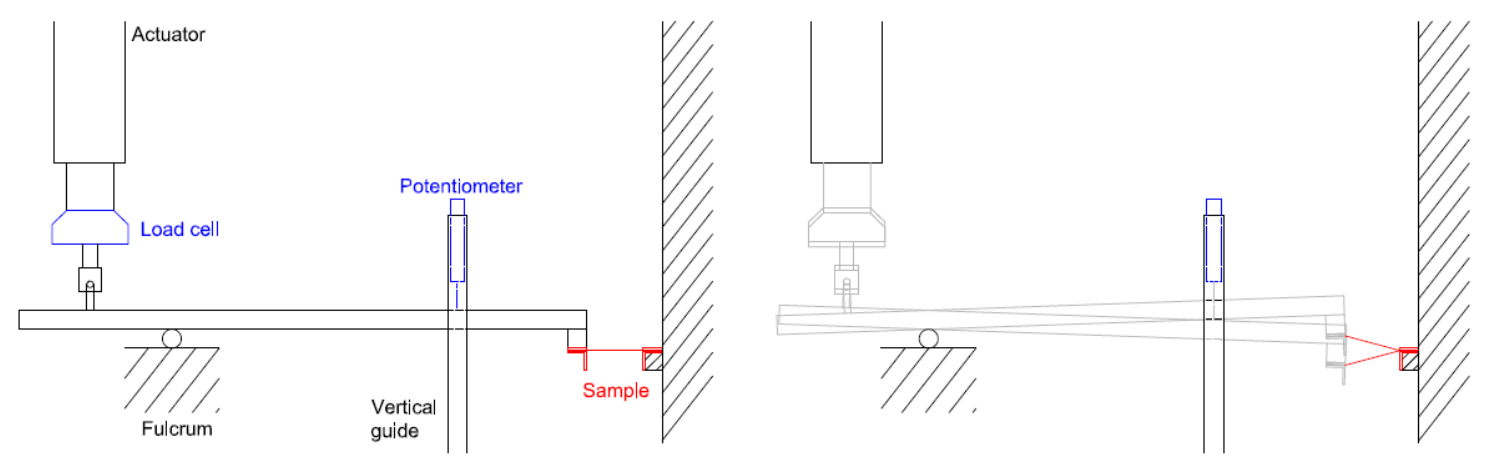

Figure 6. Sketch of the test setup for the dynamic experiments on the mesh connection elements 

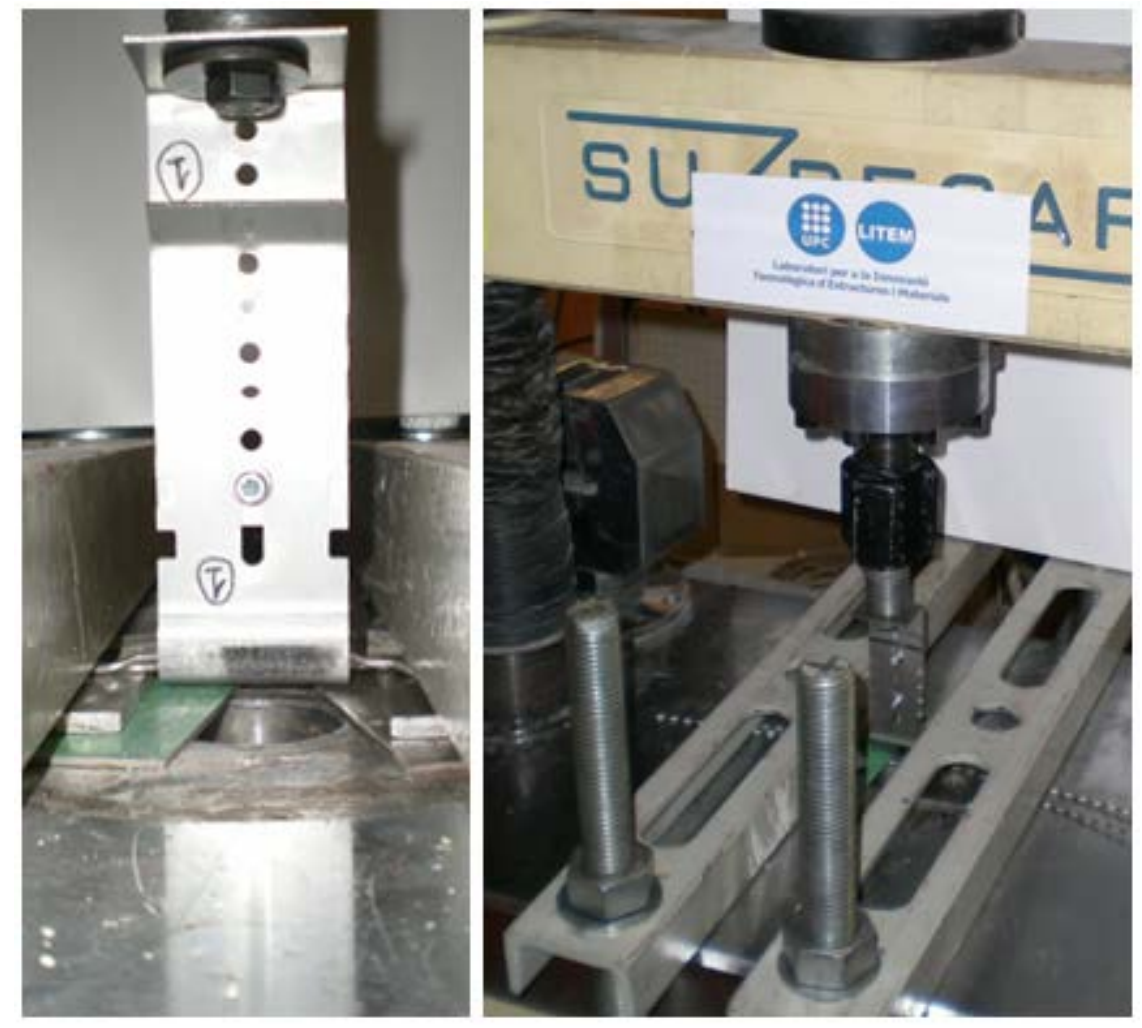

Figure 7. Retention element (left) and corresponding test setup (right)
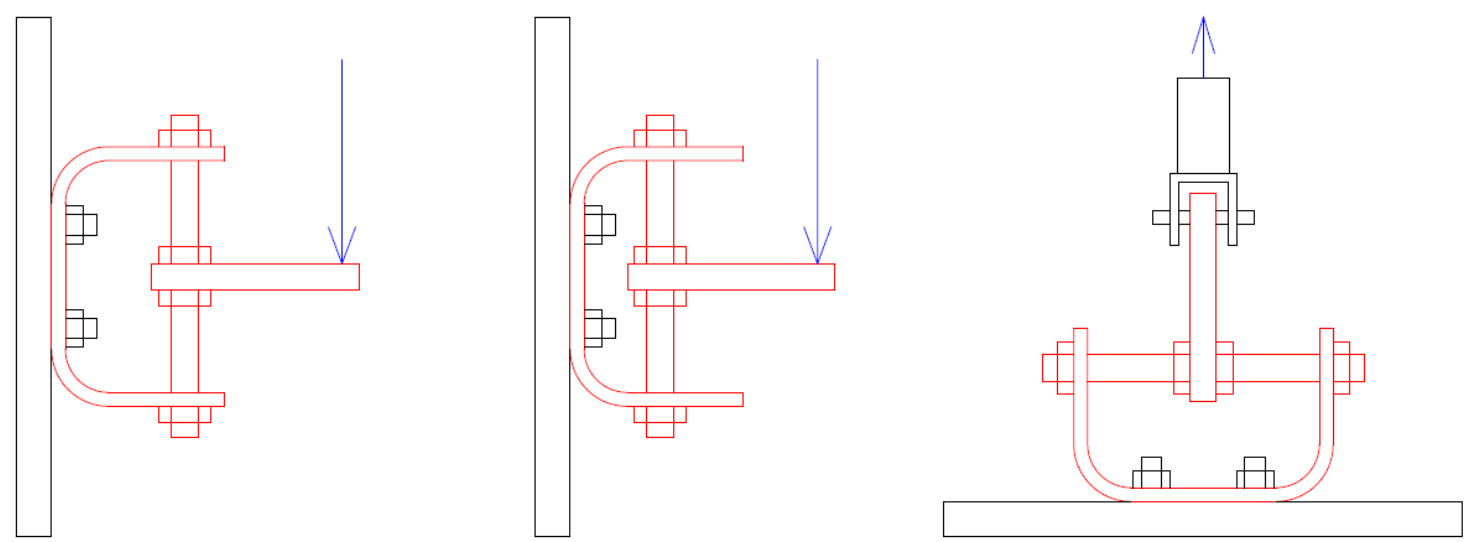

Figure 8. Sketch of the tests setups on hanging elements. From left to right, test T1 on sample configuration S2, test T1 on sample configuration S1 and test T2 on sample configuration S2 


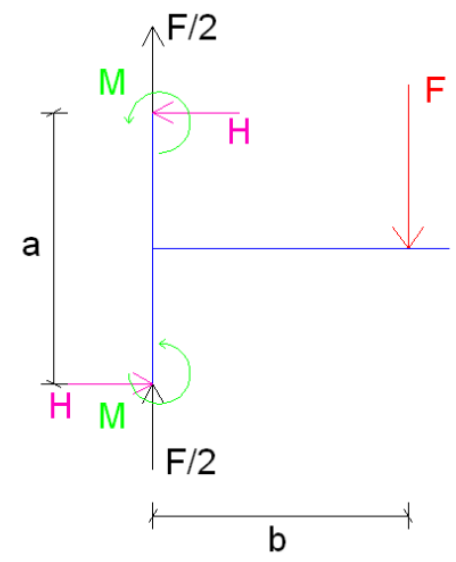

Figure 9. Sketch of the equilibrium forces

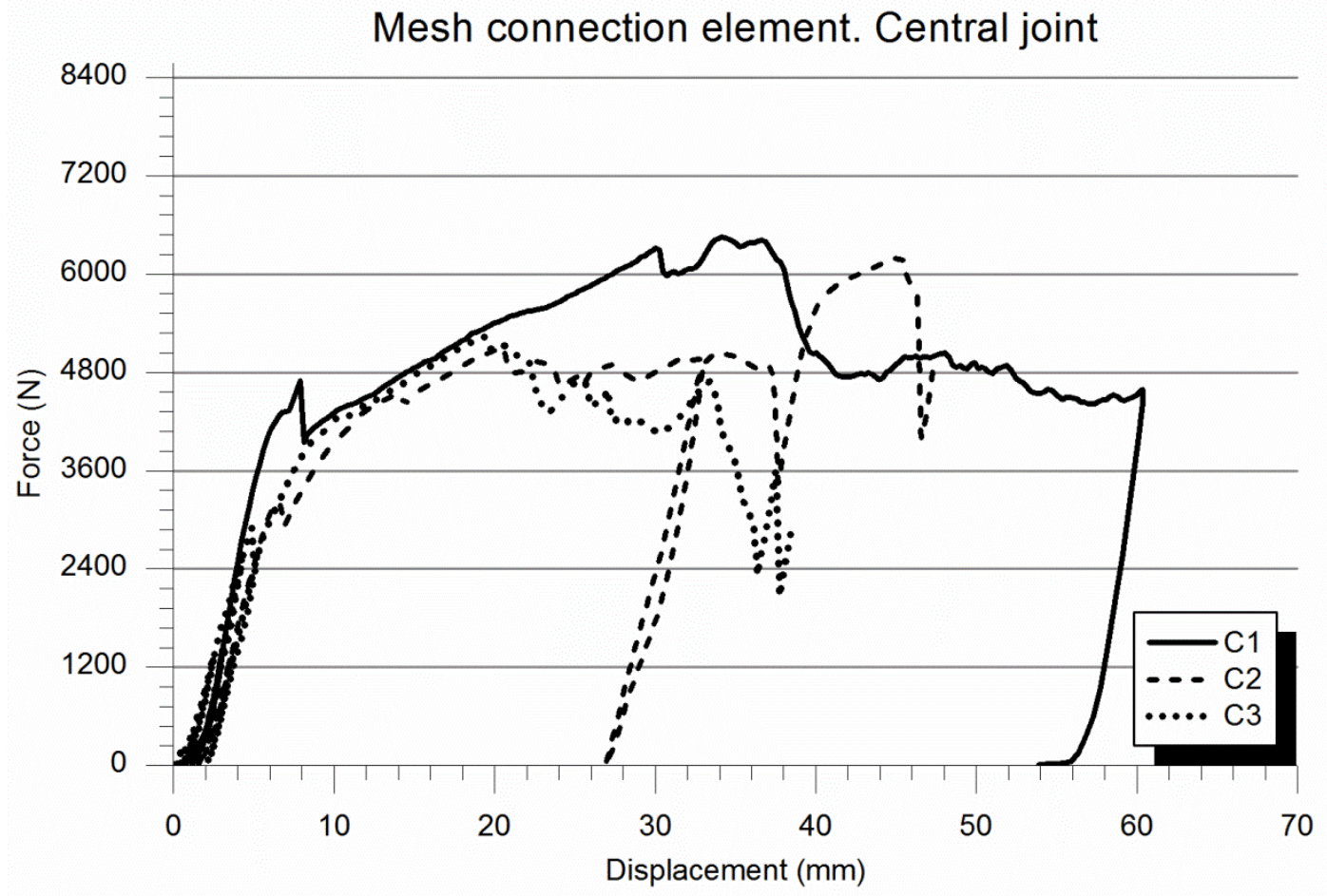

Figure 10. Force-Displacement behaviour of the mesh connection element corresponding to a central joint 

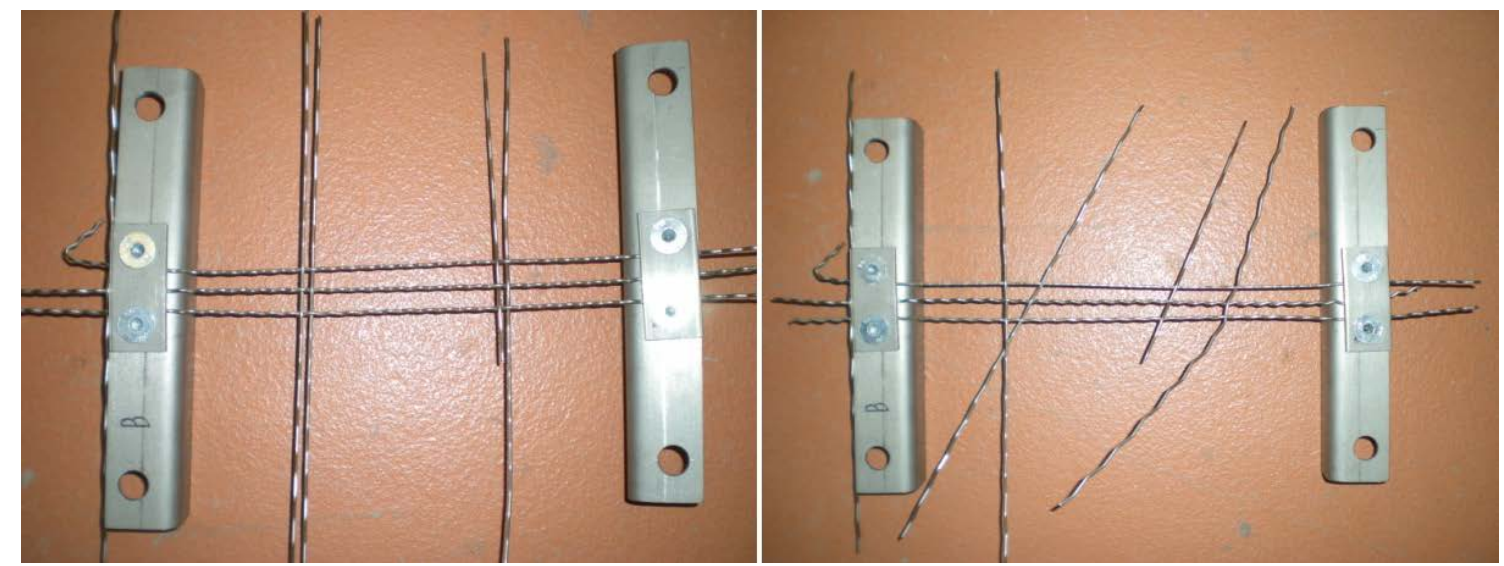

Figure 11. Initial (left) and final (right) state of the mesh connection element C2

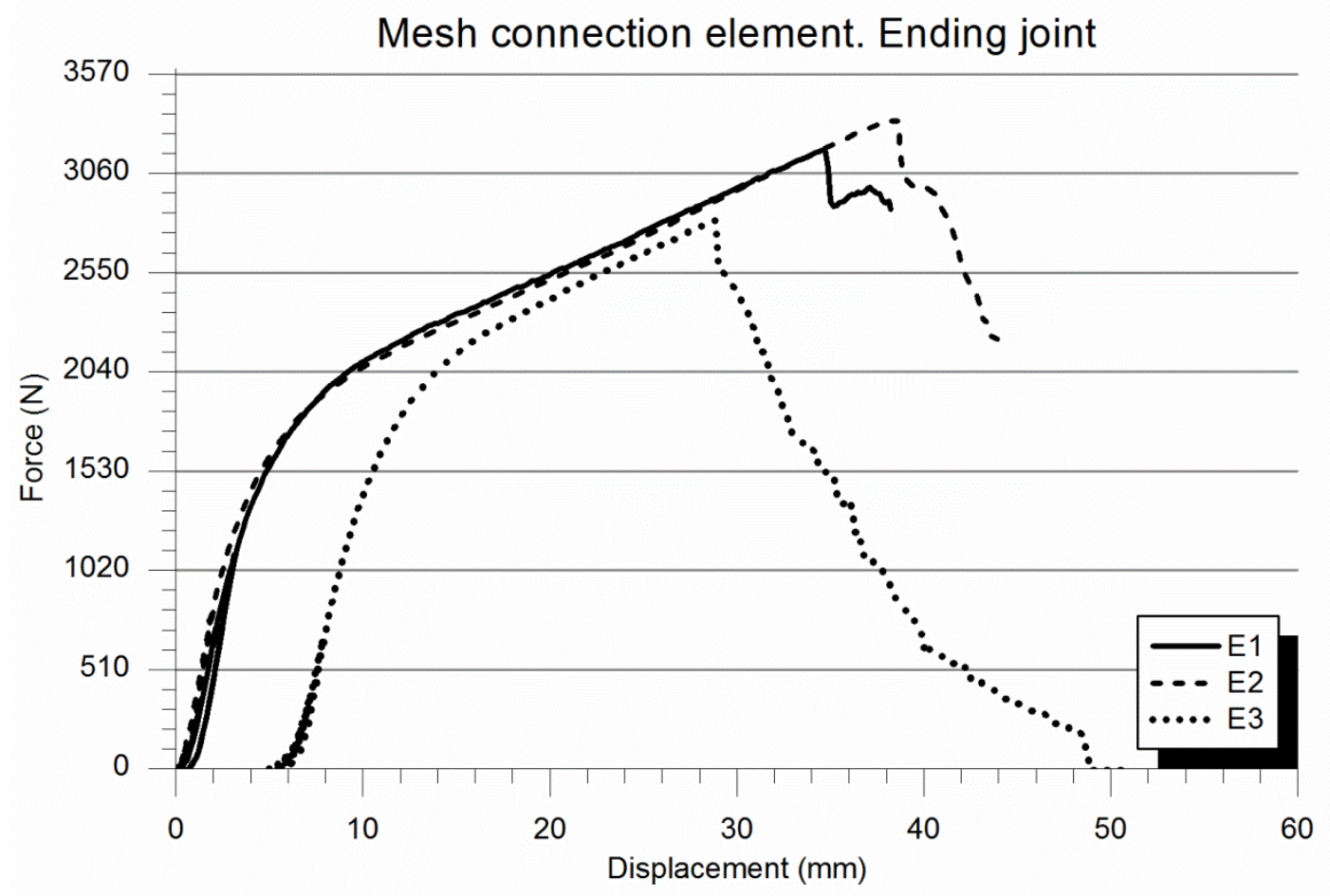

Figure 12. Force-Displacement behaviour of the mesh connection element corresponding to the end joint 

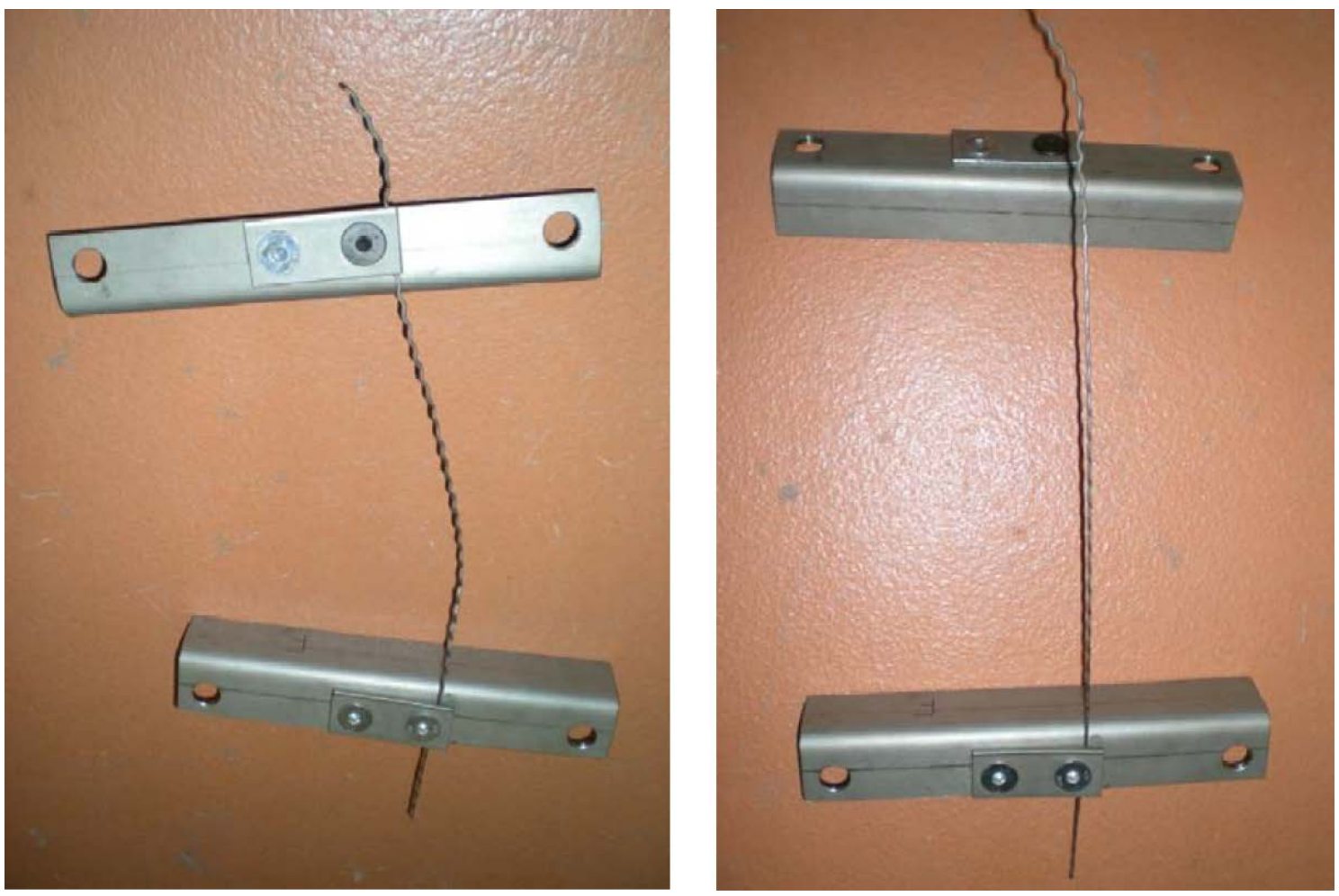

Figure 13. Initial (left) and final (right) state of the mesh connection element E3

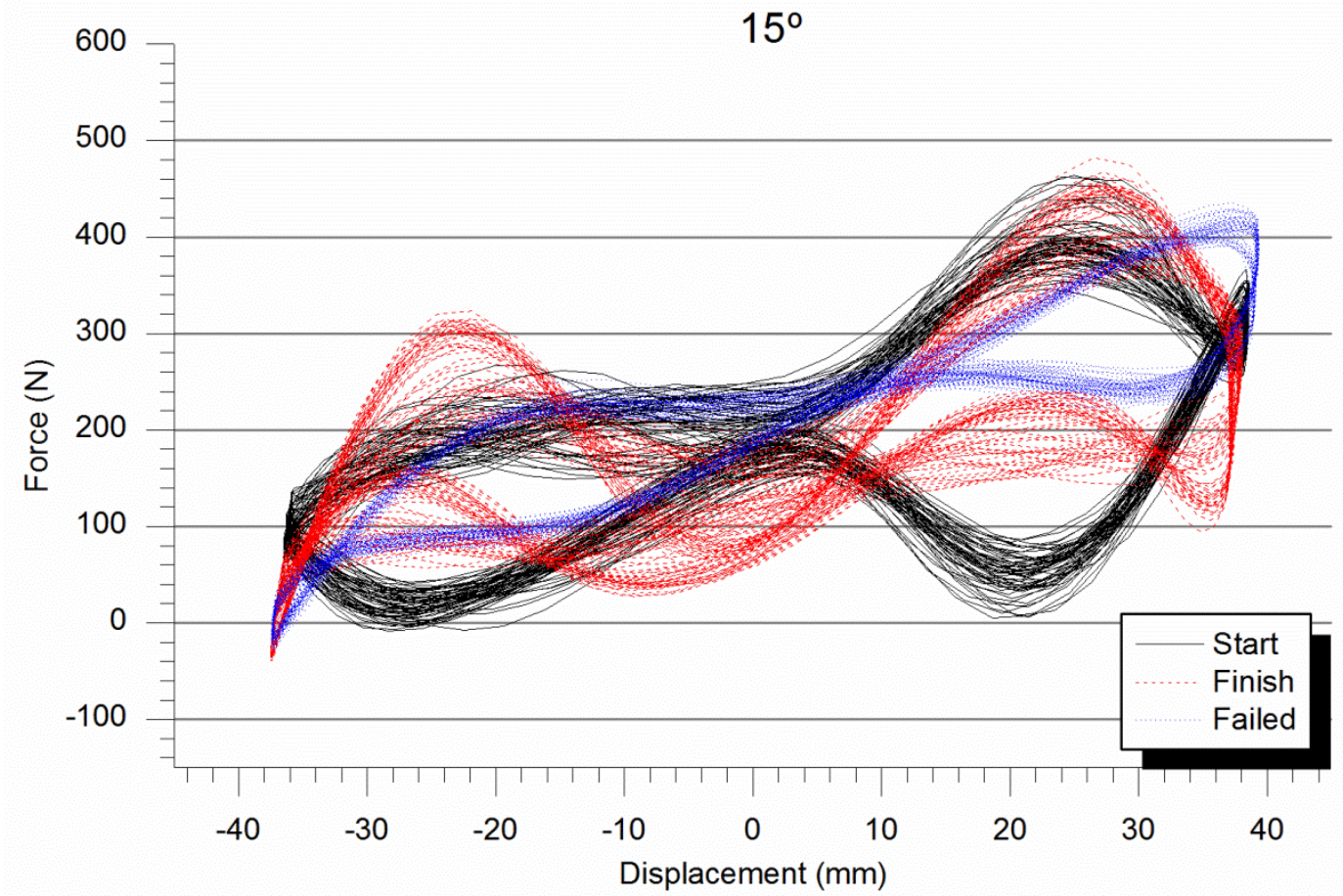

Figure 14. Force-displacement response of the free of the sample E4 at the beginning of the test, near the failure and once the element failed 


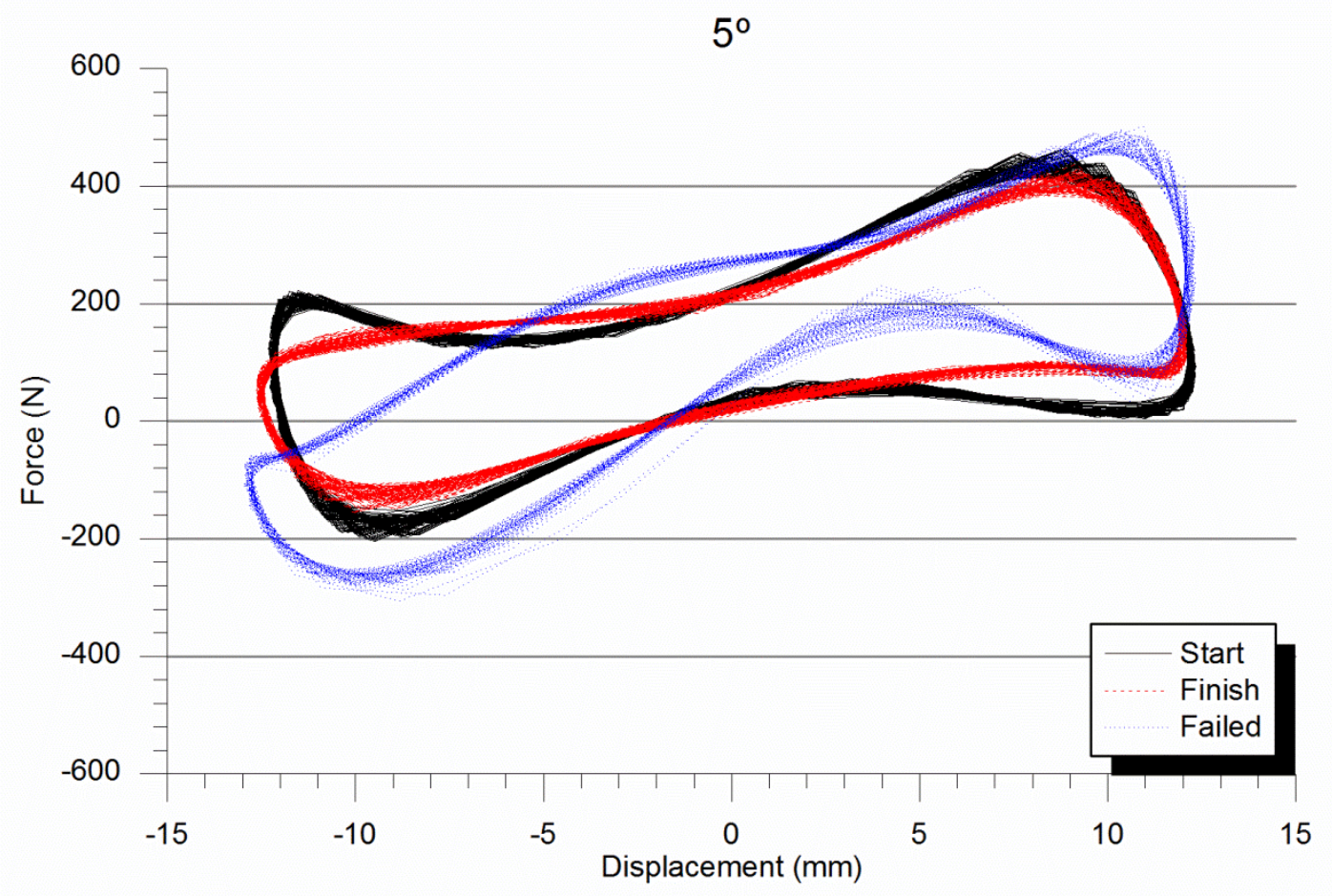

Figure 15. Force-displacement response of the free end of the sample E5 at the beginning of the test, near the failure and once the element failed

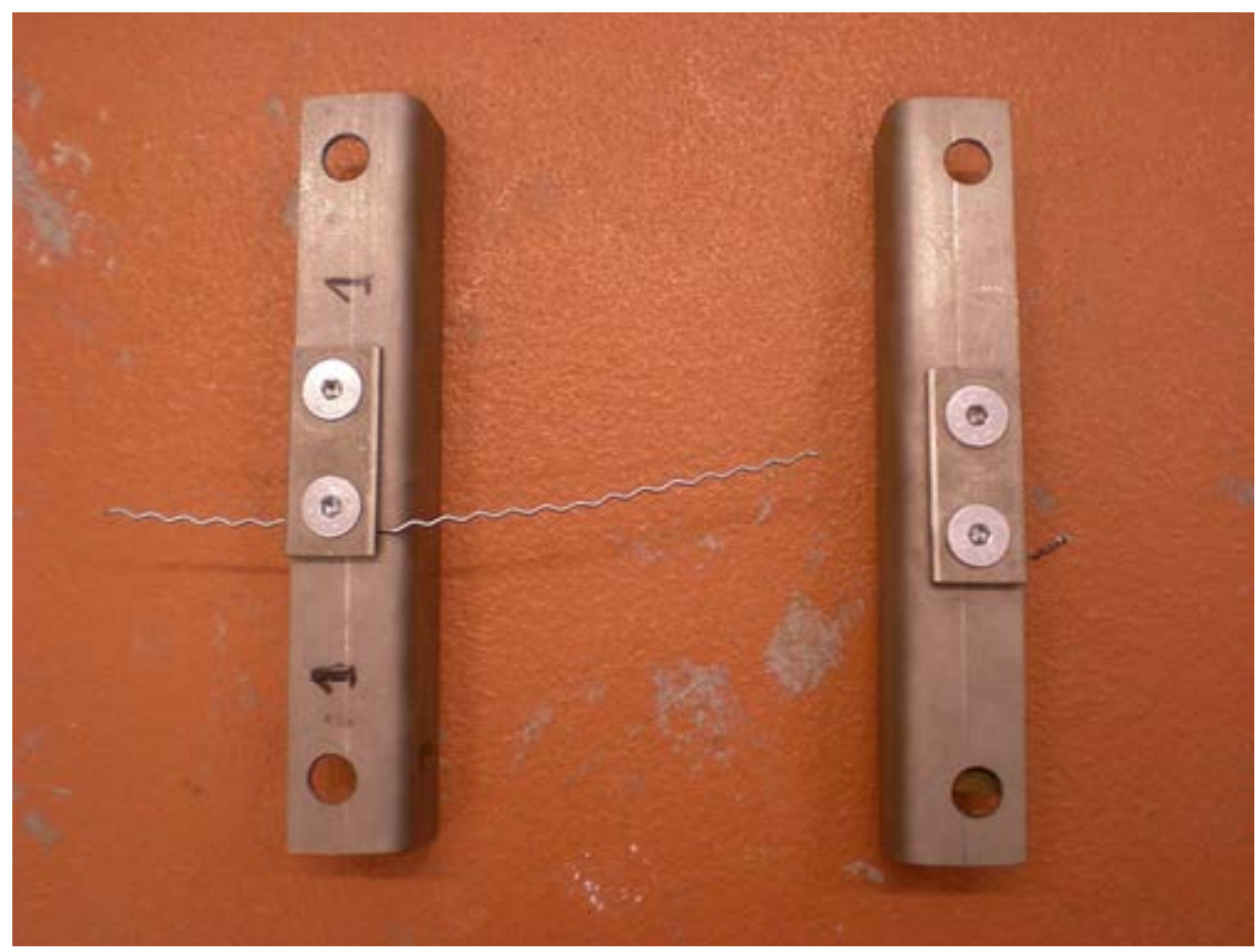

Figure 16. Final state of the sample E5 which failed by fatigue 


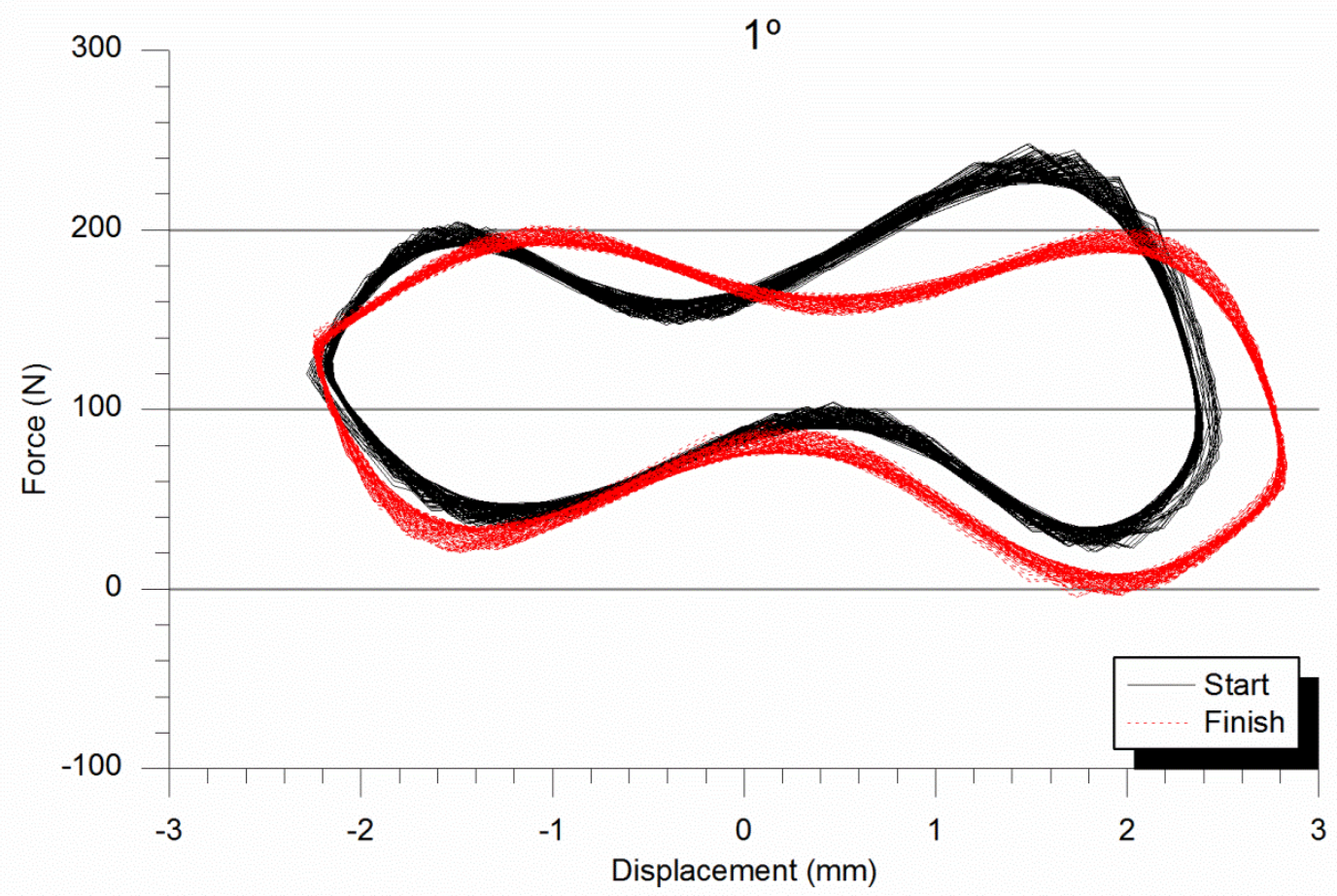

Figure 17. Force-displacement response of the free end of the sample E6 at the beginning of the test and after 10000 cycles.

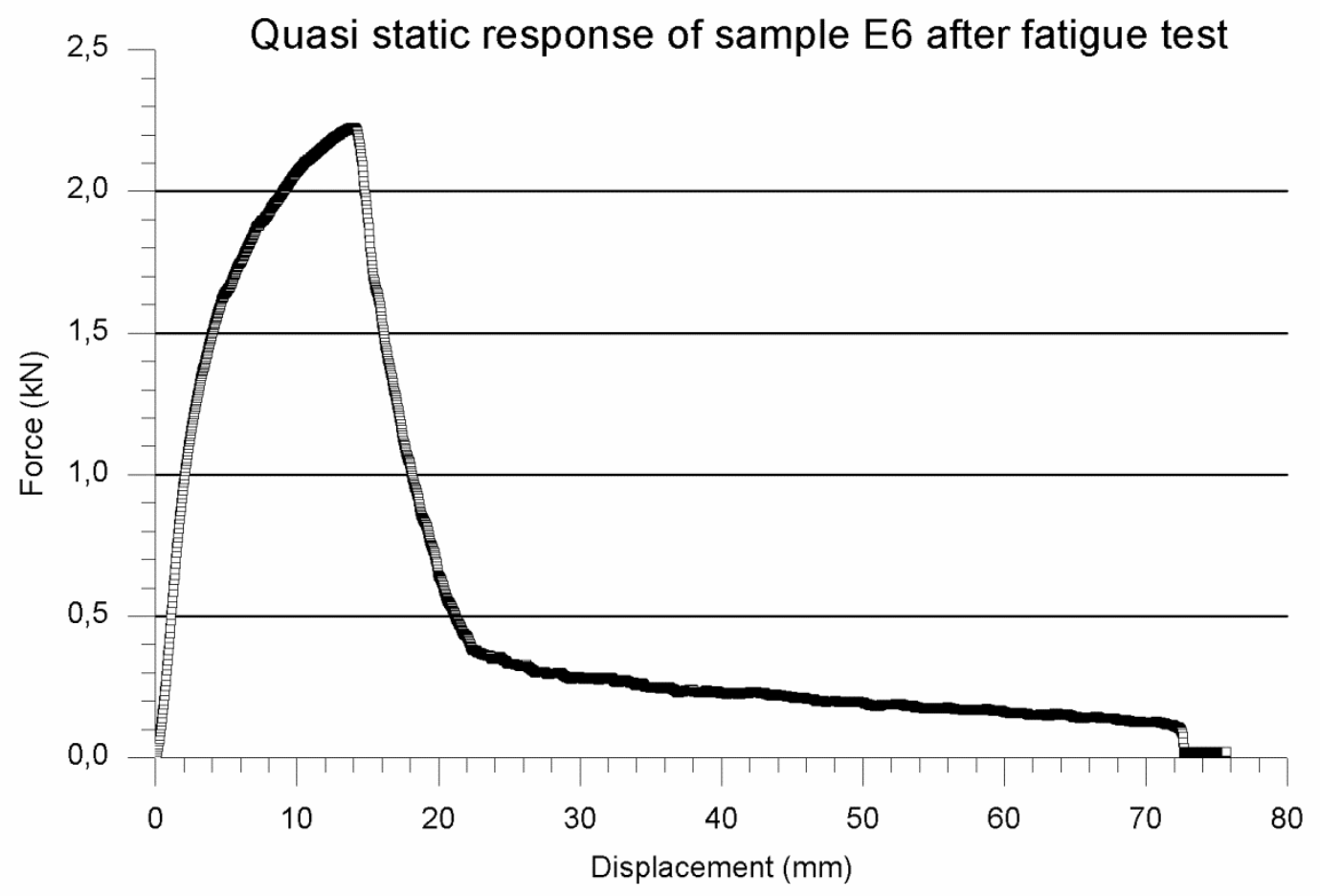

Figure 18. Tension-displacement of the sample E6 quasi-statically tested after the dynamic test 


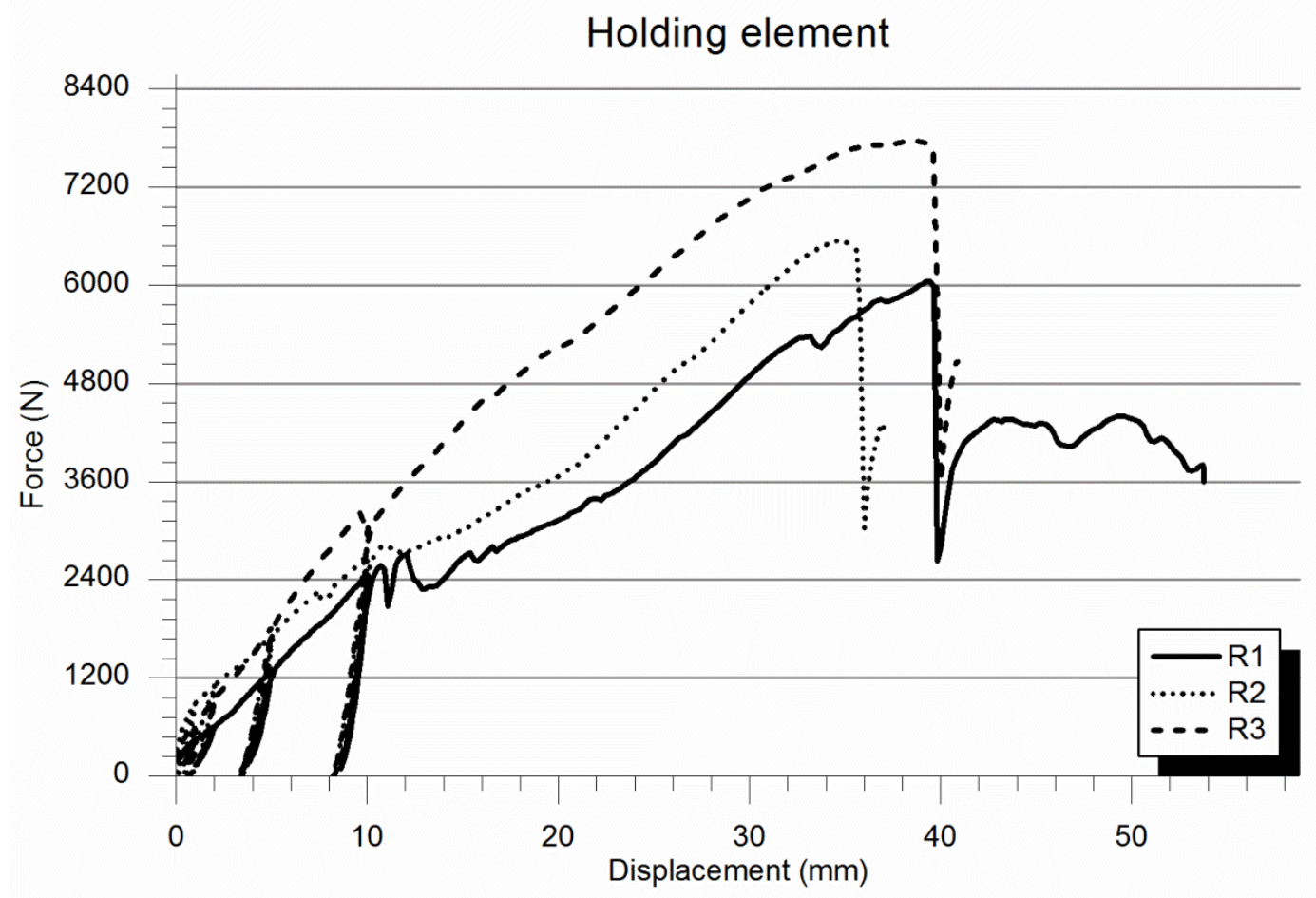

Figure 19. Experimental tensile response of the retention elements R1, R2 and R3
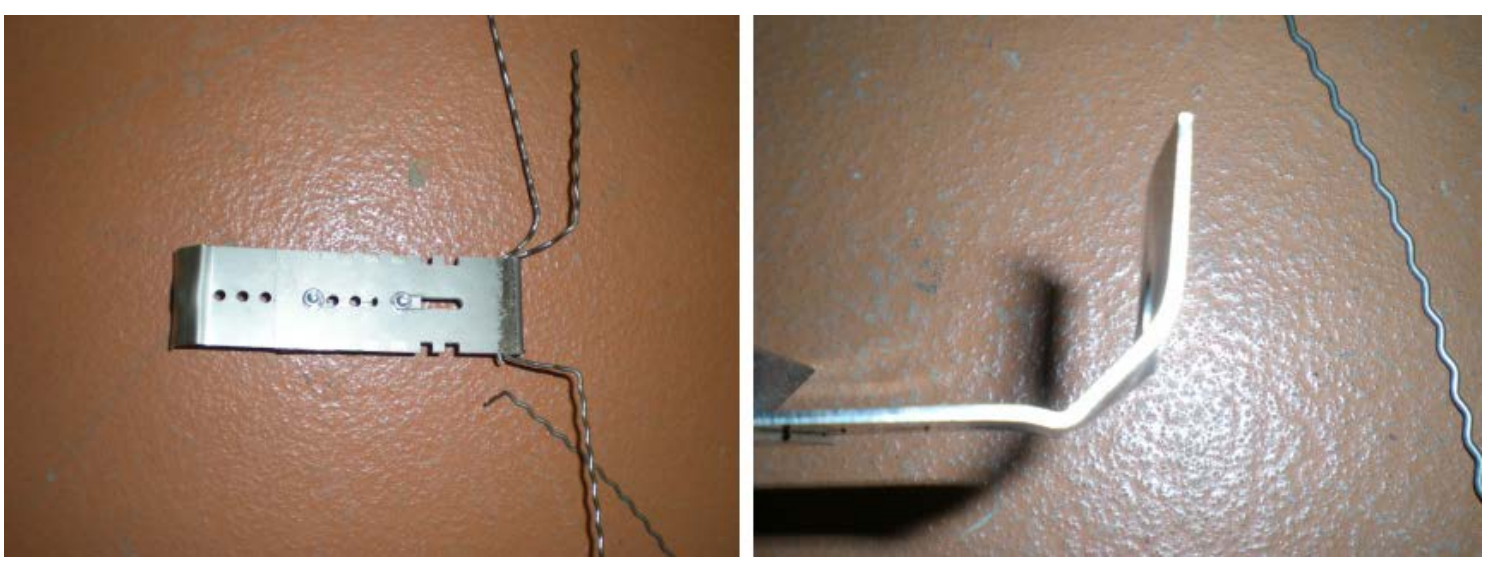

Figure 20. Retention element failure mode (left) by breaking the TCT wire and " $\mathrm{L}$ " profile bending (right) produced before failure 


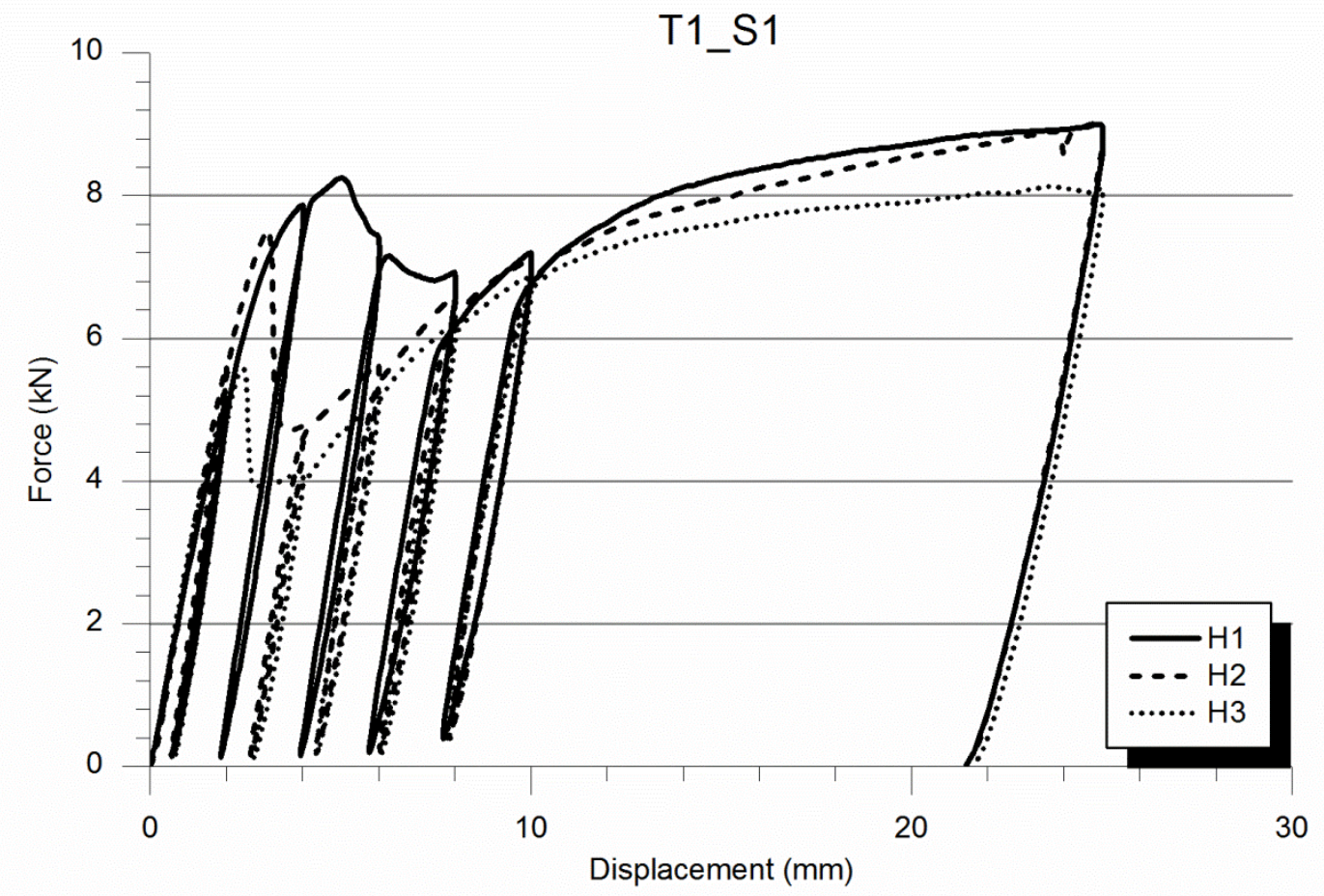

Figure 21. Experimental response of the hanging element with configuration S1 when loaded according with test setup T1

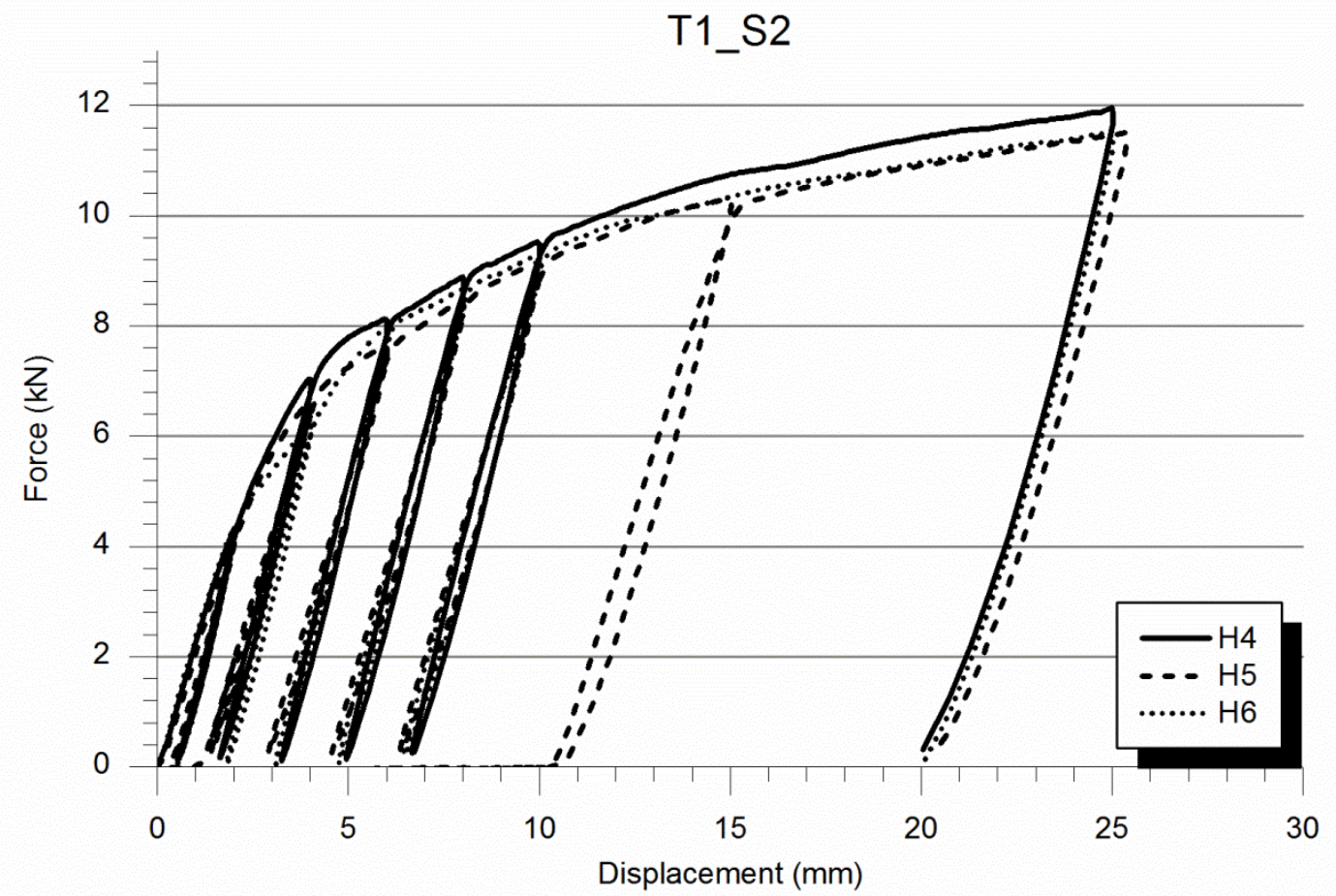

Figure 22. Experimental response of the hanging element with configuration S2 when loaded according with test setup T1 

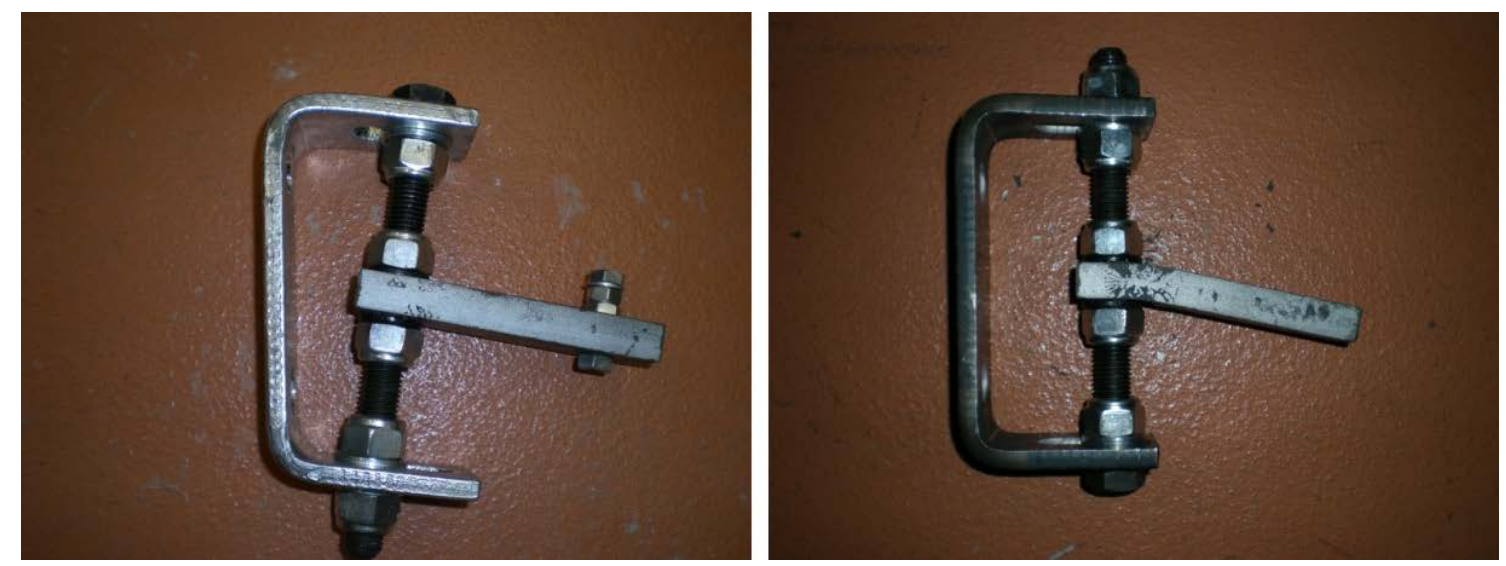

Figure 23. Failure mode of samples H2 (T1_S1) and H4 (T1_S2)

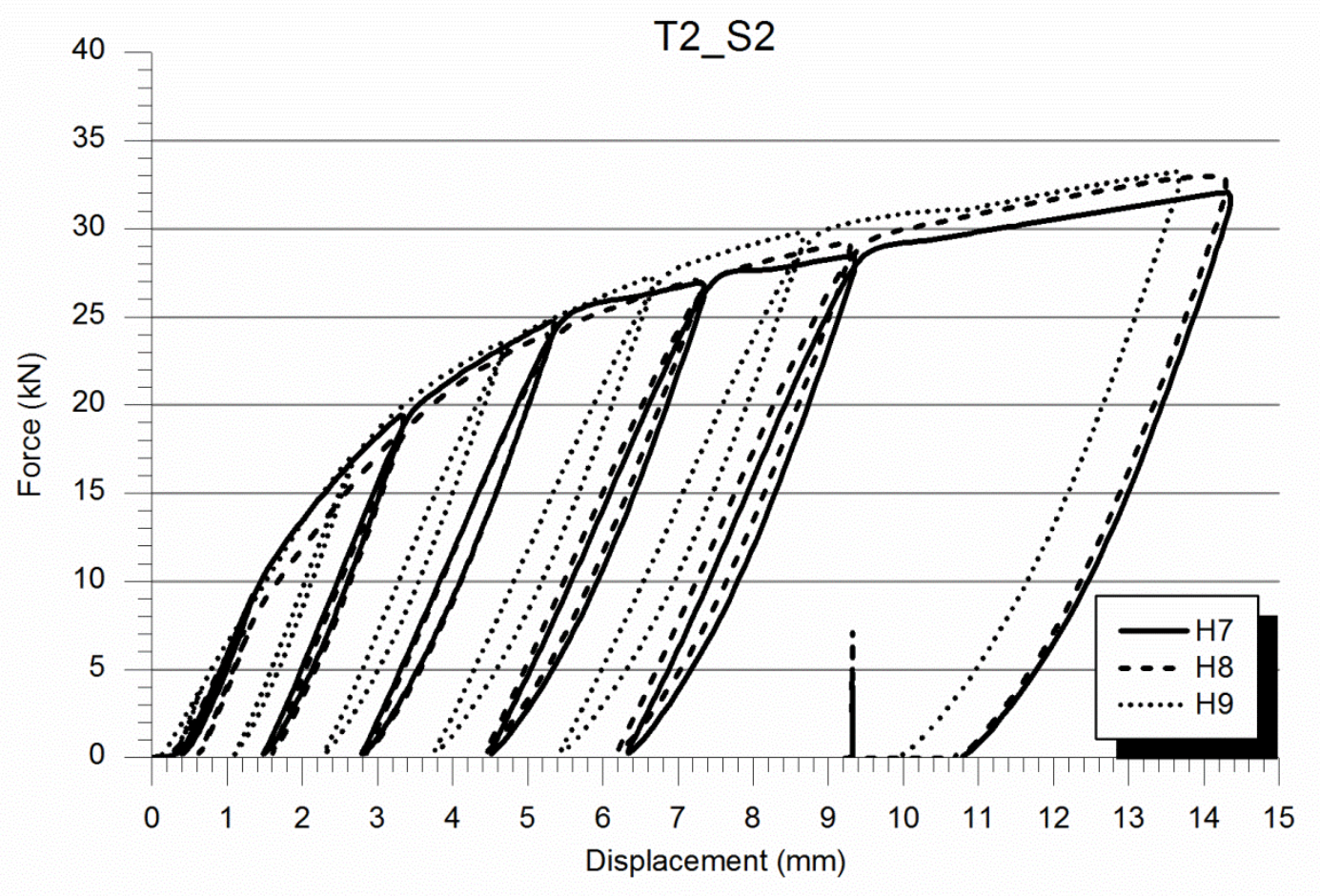

Figure 24. Experimental response of the hanging element when loaded according with test setup T2 (sample configuration S2) 


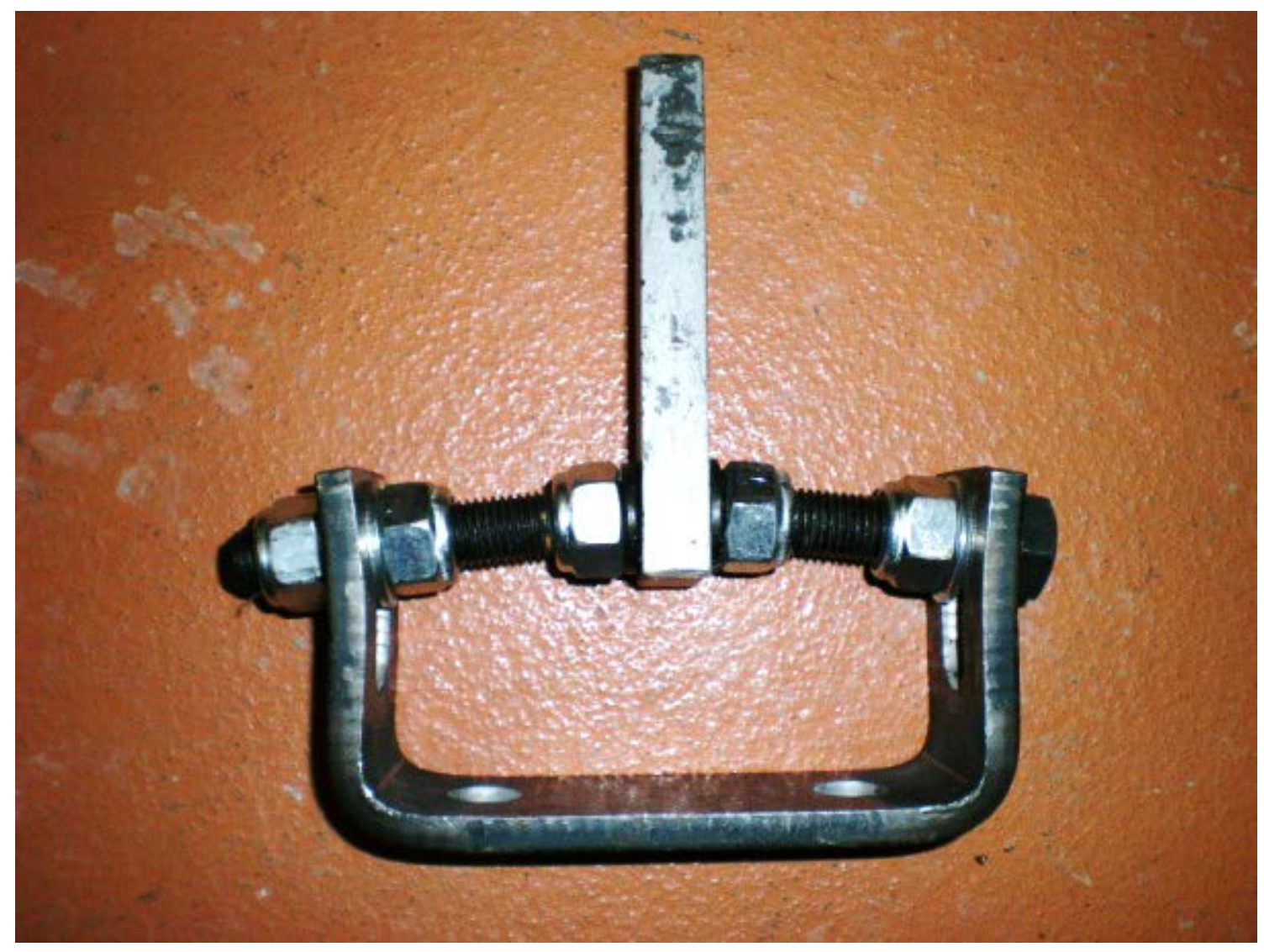

Figure 25. Failure of the sample $\mathrm{H}$, hanging element, under horizontal loads (T2) 